\title{
Learning in Multilateral Trade Negotiations: Some Results from Simulation for Developing Countries
}

\author{
Cédric Dupont \\ Graduate Institute of International Studies, Geneva \\ Cosimo Beverelli \\ Pompeu Fabra University, Barcelona \\ Stéphanie Pézard \\ Graduate Institute of International Studies, Geneva
}

Prepared for a Conference on

Developing Countries and the Trade Negotiation Process

UNCTAD, 6-7 November, 2003, Geneva

DRAFT, 10/19/03

Please ask the authors' permission before citing.

Comments welcome. dupont@ hei.unige.ch, cosimo.beverelli@upf.edu, pezard0@hei.unige.ch 


\section{Introduction ${ }^{1}$}

Whereas there are still many gaps in our understanding of negotiation processes, one well-established pattern is that the way negotiators communicate and interpret information does matter, and co-determines both the process and outcome of bargaining. In the study of international negotiations, authors have particularly focused on how actors behave when they have, at the beginning of the process, limited information regarding the resources and resolve of negotiating partners as well as on their domestic context. A large body of literature has explored such situations with the use of formal game-theoretic analytical tools, making use of so-called incomplete information models to derive consequences of limited information on actors' strategies. Incomplete information about domestic politics has been a particular focus of study, especially since the advent of the two-level game metaphor (Putnam 1988), which gave a new start to an older research tradition on domestic politics and international negotiations (Schelling 1960, Iklé 1964). Authors have paid particular attention to the influence of domestic feasibility sets, win-sets in Putnam's words, on international negotiations, ${ }^{2}$ starting from the assumption that negotiators can never, or at least very rarely, know exactly the domestic constraints of their counterparts, and may also have difficulty with their own constraints. While that recent formal work has helped to better determine the conditions of applicability of Schelling's famous strength in (domestic) weakness, it has remained problematic, to say the least, for many analysts, observers and practitioners of international

\footnotetext{
${ }^{1}$ This article is built around simulation exercises conducted within the programs of the Training Institute of the WTO. We thank the WTO for allowing us to observe those exercises for researchrelated purposes and Gilbert Winham for allowing us to interfere in the exercise that he designed. We are grateful to John Odell for valuable comments and suggestions on a first draft of this paper, to Christoph Zulauf for valuable research assistance and to the Geneva Academic International Network (GIAN) for financial support.
} 
negotiations. We see two main reasons for this. A first one is linked to what Allan and Dupont (1999) call the lack of robustness of most game-theoretic models that use advanced solution concepts (relying on refined criteria for unexpected behavior) for reducing indeterminacy in complex settings. Particularly problematic are the rationality demands placed upon negotiators who are assumed to be very sophisticated maximizers, carefully updating any piece and bit of information that they get. There is a kind of sophistication to the square. Actors are assumed to form sophisticated beliefs about the state of the world and to change them in sophisticated fashion. A second reason is that game-theoretic models have almost uniquely looked at bilateral bargaining processes, ${ }^{3}$ mostly due to the technical limits, or deficit, of game theory for situations of multiple actors.

One response to these problems has been to rely on less demanding formal tools, in particular those stemming from the negotiation analytic tradition pioneered by Raiffa (1982). As John Odell's recent book (2000) shows, those tools connect better to empirical developments than most game theoretic constructs. Yet, on the particular issues of limited information and multilateralism mentioned above, they are far from convincing, as Odell acknowledges in his concluding chapters. The focus on two actors is much neater, and simpler, analytically speaking, and the study of beliefs cannot really be endogenized, making any claim sound ad hoc.

Another response has been the development of evolutionary game theory based on the large experimental literature on coordination games (Crawford 1990, 1995; van Huyck et al. 1990, 1991, 1997). Taking inspiration from the early work of Simon $(1955,1959)$ this literature has developed and tested various "learning

\footnotetext{
${ }^{2}$ See for instance the work of Iida (1993), Milner (1997), Milner and Rosendorff (1997), Mo (1994, 1995), Pahre (1997) as wel as my own prior work (Dupont 1994a, 1994b), Dupont and Sciarini (1995, 1998).
} 
mechanisms." Relaxing some restrictive conditions of standard game theory (see Young 1998, Foster and Young 2003), no fixed number of players, no hyperrationality, and a less demanding updating of beliefs, has helped produce more realistic models of convergence toward an outcome. Yet, it is striking the extent to which communication is absent in this literature. Coordination remains a very tacit process based on probabilistic estimate of the others' behavior. There has not been much response in that literature to the question of how individuals process information and how this leads them gradually to an outcome.

There is thus a fundamental need for further work that would help design analytical tools that could simultaneously model multiple actors with endogenous beliefs. Such a goal will remain elusive if one does not accept a range of simplifying assumption. Advanced mathematics will not be a solution without those assumptions, unless one is willing to accept large-scale indeterminacy. The question is therefore to determine what are, and should be, the appropriate simplifications. While some could be theoretically derived, we claim that careful and precise empirical observations are necessary. There has been so far a striking lack of data collection for assessing the influence of beliefs on negotiation processes. Studies using formal tools have either remained mostly abstract or have focused on a few case studies as plausibility probes for the hypotheses derived from the game-theoretic models. Furthermore, there has been a clear emphasis on developed countries, in particular the USA and European countries. In our view, such a bias has to be remedied, not only for improving our understanding of how developing countries fare in negotiation processes but also for

\footnotetext{
${ }^{3}$ For exceptions see Bueno de Mesquita (1990), and Morgan (1994).
} 
our general understanding of the impact of limited, or biased, information in international negotiations.

Indeed, within the context of the work cited above, a focus on developing countries may bring significantly different lessons than developed countries. There are at least three reasons for this: (a) developed countries tend to have more transparent domestic political systems, which makes them "easier" cases for two-level games, and therefore tend to skew the analytical focus on beliefs about domestic political constraints; (b) developed countries can "afford" to carefully process and update information during negotiation processes simply because they have the required expertise and staff; lacking such an expertise and such a staff, developing countries may simply pay less attention to information problems. From a positivist perspective, this implies that it is misleading to try to use beliefs to explain developing countries' negotiation behavior. From a normative, prescriptive (policyscience) perspective, this could mean that there is urgent need for developing countries to acquire expertise in information processing and updating; (c) generally speaking developed countries tend to be stronger actors who, in the context of gametheoretic models, discount less future agreements; existing models (see in particular Dupont 1994a, 1994b) reveal a clear difference between such actors and weaker ones in terms of both negotiation offers, content and timing of agreement.

To begin sorting out these different issues, this paper provides preliminary evidence from simulated worlds. It makes use of simulation exercises conducted by the Training Institute of the World Trade Organization (WTO) for participants from the developing world. The approach borrows from the tradition of laboratory 
experiments for negotiation processes, ${ }^{4}$ while being closer to reality because individuals that participate in simulated trade negotiations are officials from member states, and therefore very likely either to participate in similar real negotiations in the future (if not already in the past). Furthermore, in contrast to standard laboratory experiments that rarely last more than one hour, the simulation exercises run over several days are not under the permanent control of observers. Apart from a few prefixed meetings, participants are free to organize the negotiations the way they judge most appropriate. In practical terms, this has made observation more difficult, and more time consuming, but also empirically richer than in standard laboratory experiments.

The paper first describes the basic features of the simulation exercise and the research questions that it helps explore. It then turns to the results obtained from a first series of experiments fom December 2002 to June 2003. We first address the question of whether there is indeed some learning by actors during the negotiation. Then we turn to the learning dynamics and in particular on factors that can be expected, according to the literature, to have an impact on the process of learning. We conclude with a summary of our main results and with suggestions for the continuation of our work.

\section{Features of the Simulated World and Research Questions}

\section{Simulation protocol}

We conducted our observations on an existing simulation exercise, the so-called Trade Negotiation Simulation Exercise (TNSE) as used at the WTO Training

\footnotetext{
${ }^{4}$ See in particular the work of Alvin Roth, including Roth $(1987,1988)$ and Roth and Murnighan
} 
Institute. The TNSE (Trade Negotiations Simulation Exercise) is designed to be a realistic simulation of trade negotiations. It involves the participation of four fictional countries, two developed, named Alba and Tristat, and two developing ones, named Medatia and Vanin, and consists of two nested exercises: a negotiation over tariff reductions and the redaction of a subsidy code.

For each country the team consists of a Minister, an Ambassador who usually acts as chief negotiator, a tariff expert, a non-tariff expert, and at least one counsellor. Participants approach the TNSE with a reasonable amount of information. They know the characteristics of their own country, as well as those of the others, both in terms of levels of development (i.e. GDP) and existing trade policies. As soon as they receive Cabinet Orders (that Ministers are free to modify before passing them to the Ambassador), negotiating teams acquire a knowledge about: a) the products/sectors in which tariff concessions can be granted by their own country; b) the products/sectors in which their own country is asking trade partners to liberalize their tariff policy; c) the ne gotiating guidelines for the subsidy code.

The participants to the TNSE are diplomats from developing countries enrolled in a course at the WTO Training Institute prior to this exercise.

Several features of the exercise work towards making it as realistic as possible:

- Strict "Cabinet Orders", serving as negotiating guidelines and constraints, and that Ministers transmit to their negotiating teams;

- A certain freedom in the organization of teams, where the Ambassador can be either a mere coordinator or the leader of negotiations;

- Strong time pressure, for the agreement, if agreement there is, must be concluded within three days ${ }^{5}$. Teams are constantly reminded of the deadline (strictly enforced) during the course of the exercise ${ }^{6}$;

(1982).

${ }^{5}$ This time pressure is also highlighted by the results of the debriefing questionnaires on the estimated sources of inefficiencies in the negotiation: the proposition "Lack of time to explore further negotiating opportunities" was consistently mentioned as one such source of inefficiency ( ${ }^{\circ} 2: 8$ yes, 6 no; $n^{\circ} 3: 13$ yes, 5 no; $n^{\circ} 4$ : 12 yes, 1 no; this question did not appear in the exercise $n^{\circ} 1$ ). 
- The high level of stress inherent to any serious negotiation can also be found in the exercise, despite the fact that the interests at stake are fictional. We have observed evidence of high emotional commitment to the performance of one's team (arguments, tears).

- The exercise ends with the responses of Ministers to their Cabinet, in which they report the details of the agreement reached and their ability -or not- to respect the Cabinet orders they had been given. Even though there is no actual Cabinet involved in the game, this formality aims at establishing a two-level game logic;

- According to the exercise guidelines, all countries believe in the virtues of free trade, but they have different economic, social and political interests and different levels of development, which leads to major clashes during the course of the negotiations;

- There is a President who acts as an "honest broker", facilitating the sharing of information among teams and chairing a few multilateral meetings. The Secretariat (staff from the WTO Training Institute) helps with technical aspects and logistics.

Despite all these elements, the TNSE remains a simulation, which is by definition different from reality. This gap between what can be simulated and what would happen in real negotiations derives from the following elements:

- Obviously, the interests at stake are fictitious. Thus, participants' identification with their "national interest" cannot be compared with what would happen in real negotiations;

- Ministers, who normally remain at best behind the scene, and most of times in their capitals during real rounds of negotiations, have a tendency in the TNSE to get involved in the process, and can sometimes be found to participate actively to the talks;

- There seems to be an implicit understanding that an agreement must be reached almost by any means. This may derive from the way the exercise is structured, through pressures by the Secretariat, or from elementary psychological dynamics by which the subject of an experiment wants to "succeed" and not make the whole exercise (whose purpose is to reach a multilateral agreement) fail. All these elements account for the fact that, among the numerous exercises that have been performed (including those we did not observe), few of them have resulted in failure to reach an agreement. This means that in a way the exercise artificially increases the cost of no agreement, lowering the participants Best Alternatives To A Negotiated Agreement (BATNAs) and forcing them to go beyond Cabinet Orders more than they would be willing to. This is not to say that nothing like this exists in real life (on the contrary, one can reasonably claim that negotiators always

\footnotetext{
${ }^{6}$ For instance, the date and hour at which the agreement must be signed is constantly written in big letters on the whiteboard of the room where all multilateral meetings take place.
} 
prefer success to failure), but in the TNSE the trade-off between the "happy ending" of the exercise and the preservation of the national interest leans much more towards the first element.

- The fact that, as noted above, there is no real Cabinet behind the Cabinet Orders aggravates the tendency to try to reach an agreement at any cost, since there are no considerations of accountability. In other words, all the Ministers know that whatever they accept in the name of their country in the negotiations, there will be no one to fire them once they are back in their fictional capitals.

\section{Data set}

With all these limitations in mind, we observed and studied a series of four TNSE between December 2002 and June 2003. ${ }^{7}$ These simulations have involved 99 individuals from developing countries and countries in transition. Individuals were grouped in teams of 5 or 6 that represented countries. In each exercise, participants elected one Chair for the whole process.

We carefully observed the four exercises and collected data in different ways. First, we conducted daily interviews with the Ambassadors and Ministers of each country (32 individuals). The questionnaires (see Appendix 1 and 2) aim at systematically tracing the evolution of the negotiation from the perspective of the participants. ${ }^{8}$ Most questions focus on informational issues and the way they affect the negotiation process. To avoid interfering too much with the process, interviews were meant to be very short. Second, we distributed at the end of each exercise a debriefing questionnaire (see Appendix 3) with the intention to collect overall impressions of the exercise. And third, we sat in rooms where participants were negotiating when these rooms were located in the building of the WTO. We took notes of the offers and

\footnotetext{
${ }^{7}$ These four TNSEs were respectively included in a Special Course on Negotiations (2-13 December 2002), two three-months Trade Policy Courses (English and French-speaking, 13 January - 4 April 2003), and a Special Course on Negotiations (16-27 June 2003). For the sake of brevity they will be labeled $n^{\circ} 1,2,3$ and 4 in the remaining of this paper.

${ }^{8}$ Due to our effort to improve the interview questions and the debriefing questionnaires, some elements have sometimes been changed from one exercise to the other, which explains why the results of some questions can only be analyzed for two or three exercises instead of four.
} 
requests made by countries and of the arguments behind them. For practicality reasons, the results that we discuss in the next section mostly use data from the questionnaires (with some complements coming from direct observation) and focus on the tariffs negotiations. Interpersonal coding reliability should be high given that we did all the interviews and observations.

We had no control over the selection of participants, nor on the composition of groups of negotiation. Although this may become a problem at a later stage of our research (impossibility to trace some possible variations depending on the origins of participants), it has the advantage of avoiding any intentional bias on our part. And we did get variation in terms of geographical origins (all the continents represented), in terms of training/education (economics, law, social sciences), in terms of gender, in terms of current professional status and in terms of experience in the field of trade negotiations. $^{9}$

\section{Research questions}

Our purpose in studying the different TNSEs has been to get as close as possible to the negotiators (who are not forbidden to speak because of matters of secrecy, as they could be in a real negotiation) in order to grasp their understanding of the role they see themselves playing, of the strategies that are available to them and of the way they see other countries. Negotiators must approach the talks with a more or less defined knowledge of the interests of the country they represent, and with the clearest possible

\footnotetext{
${ }^{9}$ Participants to the first and fourth exercises tend to be higher ranked diplomats or civil servants, most accustomed to a strategic approach to negotiations. From the answers given in the debriefing questionnaire to the question: "Have you ever participated in or observed any real negotiation?" we observe that 31 participants, over a total of 67 returned questionnaires, have prior negotiating experience (this represents $46 \%$ of those who responded and $31 \%$ of the participants). According the existing literature we should expect individuals to learn through experience (Bazerman et al. 1985; Neale, Huber and Northcraft 1987; Neale and Northcraft 1986).
} 
knowledge of the other(s). We are therefore interested in answering the following two sets of questions:

1. Do actors learn during the negotiation process? Do we see any evidence that dealing with partners has changed their initial apprehension of the bargaining situation?

2. How are the initial information and knowledge updated and translated into new beliefs and tactics? Do negotiators follow some pre-established cognitive heuristics, or do they simply react to the tactics adopted by other teams? What is the role of factors such as truthfulness in the learning dynamics?

These are the questions we will try to explore here, using our own observations of the bilateral and multilateral meetings, as well as the feedback from the participants we were able to gather. Although simple at prima facie, this simulation setting is already quite complex as far as beliefs are concerned. Indeed, there is a dual problem of incomplete information, both within and between parties. The setting combines features of agent-principal models as well as bilateral bargaining models. Given that there are four parties that can bargain either bilaterally, or multilaterally (at three or four), information diffusion, through signaling, can also be quite varied. ${ }^{10}$ In short, this is a very interesting setting for collecting data.

\footnotetext{
${ }^{10}$ The multiple actors setting should allow for an empirical exploration of what Lohmann (1997) calls player linkage, that is, strategies that "control" some actor through its links with other actors in the system (here in the negotiation process).
} 


\section{Evidence}

As previous exercises using the same protocol had already showed, the simulation led to different final outcomes. Countries came out with different average cuts of tariffs, different bilateral agreements, different sector agreements, as well as different texts on subsidies. Agreements follow more or less the Cabinet Orders. This clearly indicates that the simulation itself is not predetermined: Cabinet Orders are not precise or strict enough to dictate the outcome of the game. The negotiating process therefore does determine the outcome. Our focus here is on information exchange and the evolution of actors' perceptions and knowledge. Our discussion considers general trends with minimal attention paid to anecdotal evidence. We first present data that uncover a learning curve among actors and then analyze potential reasons behind particular learning patterns.

\section{Evidence of learning}

To uncover some learning attitude, we look at whether participants improve and refine their information as the simulation proceeds through time. We focus on three interrelated aspects: bottom-lines of negotiating partners, the zone of agreement and the cooperative attitude of other countries.

\section{1) Getting to Know Others' Bottom Lines}

During the tariff negotiation process, consisting primarily in a number of bilateral discussions aiming at negotiating tariff cuts sector after sector, or product after product, countries reveal progressively their position and their bottom line becomes more and more clear for their partners. We should expect this "revealing" process to be the main source of improved knowledge. 
In order to assess the learning aspect of the exercise, we ask the Ambassadors in their daily questionnaire to evaluate, on a 1-5 scale ( 1 being the minimum and 5 being the maximum), their knowledge of the maximum concessions that other countries could make. The answers were recorded for each of the three days of the TNSE, allowing us to compare the levels of knowledge (as given by the Ambassadors) over time. Table 1 provides a detailed account of how perceived knowledge of maximal concessions by Ambassadors changes in the negotiation process.

Table 1: Change in Negotiators' Perceived knowledge of others' bottom lines

\begin{tabular}{|l|c|c|c|}
\hline & $\begin{array}{c}\text { From day } 1 \text { to day } 2 \\
(\mathrm{~N}=48)\end{array}$ & $\begin{array}{c}\text { From day } 2 \text { to day } 3 \\
(\mathrm{~N}=48)\end{array}$ & $\begin{array}{c}\text { From day } 1 \text { to day } 3 \\
(\mathrm{~N}=48)\end{array}$ \\
\hline Increase & 16 & 21 & 16 \\
\hline Same & 8 & 13 & 6 \\
\hline Decrease & 11 & 6 & 8 \\
\hline Missing & 13 & 8 & 18 \\
\hline
\end{tabular}

Note: number of cases for each column corresponds to three perceptions by country times the number of exercises, that is, $3 \times 4 \times 4$. Last column looks at change between day 1 and day 3 without taking into account the situation in day 2. For details see Appendix 4.

Abstracting from relative movements, it appears that perceived knowledge of the opponents' maximum concessions does increase as the negotiation goes on. Whereas $33 \%$ of responses (16/48) on day 2 indicate an increase of perceived knowledge, the proportion goes up to $44 \%$ (21/48) on day 3. Furthermore, one should note a decrease in the number of actors who cannot or do not want to respond (27\% for the day1-day 2 transition, $17 \%$ for the day2-day3). The data indicates, however, that the increase in perceived knowledge is not linear. In particular, there seems to be a downward trend from day 1 to day 2, trend that is sometimes not compensated by an increase from day 2 to day 3 . 
We also asked Ambassadors to evaluate other Ambassadors' knowledge of the maximum concessions that their own country could make. ${ }^{11}$ This allows us to check whether the evaluation by the ambassador of Country X of Country Y's bottom lines corresponded (matched) with the evaluation by the ambassador of Country $\mathrm{Y}$ of Country X's knowledge about Country Y's bottom lines. Consistent (matching) evaluation by both sides can be considered as an indication of smooth and efficient flow of reliable information. On the other hand, a mismatch would signal the presence of a difficult to bypass biases, communication difficulties or simply misunderstandings. In Appendix 4, we present 24 tables with all the results. ${ }^{12}$ The first row of Table 2 summarizes the evidence. It can easily be seen that matching is not the rule: it happened only in 36 cases out of a total of 144 (25\%) while in 38 pairs at least one ambassador answered that he could not tell. Yet, one can see a higher rate of matching as the negotiation proceeds. For the third day, we observe 17 cases of matching out of 35 pairs $(48.6 \%)$. This percentage is significantly higher that the one observed during the first day (8 out of 30 cells, 26.6\%) or the second day (11 out of 41 cells, 26.8\%). This could be an indicator that parties, as the negotiation goes on, come to converge on their evaluation of the context.

Table 2: Mismatch and perception of bottom lines

\begin{tabular}{|l|c|c|c|c|}
\hline & $\begin{array}{c}\text { First day } \\
(\mathrm{N}=48)\end{array}$ & $\begin{array}{c}\text { Second day } \\
(\mathrm{N}=48)\end{array}$ & $\begin{array}{c}\text { Third day } \\
(\mathrm{N}=48)\end{array}$ & $\begin{array}{c}\text { Total } \\
(\mathrm{N}=144)\end{array}$ \\
\hline Matching answers & 8 & 11 & 17 & 36 \\
\hline Difference of 1 & 10 & 19 & 11 & 40 \\
\hline Difference of 2 & 6 & 8 & 5 & 19 \\
\hline Difference of 3 & 6 & 2 & 2 & 10 \\
\hline Difference of 4 & 0 & 1 & 0 & 1 \\
\hline Incomplete & 18 & 7 & 13 & 38 \\
\hline
\end{tabular}

Note: matching is defined as a situation in which the perceived knowledge by actor A of actor B's bottom lines has the same coding as the perception by B of actor A's knowledge of B's bottom lines.

\footnotetext{
${ }^{11}$ The question was: "On a 1 to 5 scale, 5 being the maximum, how would you evaluate X's knowledge of the maximum concessions that you can make?" (see Appendix 1)

${ }^{12}$ In Appendix 4, the cases of matching (in column) are highlighted.
} 
One possible objection here could be that the source of mismatch is the content and wording of the questionnaire. For instance, it is very possible that the interviewees do not attribute the same weight to the different values of the scale. It could happen that two ambassadors both think they have a very good knowledge of the concessions that the other can make, but that for one "very good knowledge" deserves a 4 (on the 1 to 5 scale) while for the other it deserves a 5 . For this reason, we refine the above analysis by looking not just at the existence of mismatches but also at the size of those mismatches. Table 2 reveals that most of the mismatches are small ones. It also shows that the downward trend observed in Table 1 from day 1 to day 2 may be misleading. The overall increase in the number of mismatches between those two days is uniquely due to the increase in the number of small mismatches, other ones decreasing.

\section{2) Viewing a zone of agreement}

To check the robustness of the first evidence of learning, we now discuss the results on a question that should be related to the bottom lines. The Ambassadors' daily questionnaires contain a question on whether they think there is a zone of agreement with negotiating partners (three possible answers: Yes, No or Do not know). Logically, based on the evidence from the previous questions, one should expect a convergent process here too. Table 3 summarizes the data that can be found in Appendix 4. 
Table 3: Answers to "Do you think that there is a zone of agreement with X?"

\begin{tabular}{|c|c|c|c|}
\hline & $\begin{array}{c}\text { Day 1 } \\
(\mathrm{N}=48)\end{array}$ & $\begin{array}{c}\text { Day 2 } \\
(\mathrm{N}=48)\end{array}$ & $\begin{array}{c}\text { Day 3 } \\
(\mathrm{N}=48)\end{array}$ \\
\hline Yes & 22 & 28 & 33 \\
\hline No & 5 & 6 & 4 \\
\hline $\begin{array}{c}\text { Do not know or no } \\
\text { answer }\end{array}$ & 21 & 14 & 11 \\
\hline
\end{tabular}

Note: number of cases is the product of three answers times four countries times four exercises for each day

Very clearly, negotiators become more optimistic about the existence of a zone of agreement as the process goes on. Not only the number of "Yes" increases, but also the numbers of "Don't know" and "No" decrease. The "down and up" trend observed above has not disappeared but is not significant.

As for our discussion of bottom-lines, we now assess the question of the zone of agreement on a dyadic basis, rather on an individual basis. Specifically, for each pair of countries we see whether both countries come up with the same answer (either Yes-Yes or No-No), with an opposite answer (Yes-No or No-Yes) or simply an incomplete answer (one of them at least not answering the questions).

Table 4: Dyadic evaluations of the zone of agreement

\begin{tabular}{|c|c|c|c|}
\hline & $\begin{array}{c}\text { Day 1 } \\
(\mathrm{N}=24)\end{array}$ & $\begin{array}{c}\text { Day 2 } \\
(\mathrm{N}=24)\end{array}$ & $\begin{array}{c}\text { Day 3 } \\
(\mathrm{N}=24)\end{array}$ \\
\hline Yes-Yes & 8 & 8 & 13 \\
\hline No-No & 0 & 0 & 0 \\
\hline Yes-No and No-Yes & 2 & 3 & 10 \\
\hline $\begin{array}{c}\text { At least one No } \\
\text { answer }\end{array}$ & 14 & 13 & 1 \\
\hline
\end{tabular}

Note: number of cases is the product of six bilaterals times the number of exercises for each day

As in the case of the evaluation of maximum concessions, the incidence of mismatch is lowest on the third day of negotiations, indicating the progressive acquisition of common knowledge. Parties very rarely come up with a different assessment of the existence of a zone of agreement and never mutually come up with 
a negative answer. In addition, the number of "Do not know" or missing answers diminishes with time. It is also relevant to point out that only in one case did we observe more than one mismatch in the same bilateral relationship: this was MedatiaVanin in exercise $n^{\circ} 3$, where Medatia's optimism was contrasted by Vanin's reiterated pessimism about the prospects of reaching a bilateral tariff agreement.

\section{3) Cooperative attitude}

Change was also perceptible in the answers to the questions: "Which country do you find the most cooperative? Which country do you find the least cooperative?" Looking at the time series for each country across the four exercises (32 observations), $56 \%$ (18) of them show change, $22 \%$ (7) no change at all and $22 \%$ (7) are incomplete. So clearly negotiators modify their evaluation of their partners across time.

Another, less straightforward, way to uncover change on that dimension is to check if there is an increasing number of dyads with mutually compatible evaluation, that is, dyads in which both actors either declare each other as the most or the least cooperative. As can be seen from the data in Appendix 5, such a trend slightly appears, in particular if we contrast it to dyads with diametrically opposed evaluations. ${ }^{13}$ Indeed, during the interviews on the first day, there were 3 matching pairs and 3 non-matching pairs. On the second day, there were five matching pairs and three non-matching pairs. On the third day, there were still five matching pairs, but no non- matching pair. 
Overall, the results derived from the daily interviews with the ambassadors indicate that there is a learning process that operates during the course of the exercise: actors gain new information about their negotiating partners - an information that progressively tends to become common knowledge - and update their beliefs according to it. Our data suggest that with time negotiators' views converge in a threefold manner: a) there is a narrowing of differences between perceived knowledge of maximum concessions and evaluations of that (actual) knowledge by the opponent; b) we see an increase in number of pairs of negotiators agreeing on the existence of a zone of agreement; c) there is an increase in pairs mutually designating each other most/least cooperative.

Hence our results so far seem on the one hand to give empirical credit to models or theories that posit that actors learn throughout a negotiation process. Moreover, as indicated in some game-theoretic (standard or evolutionary types), learning is not a smoothly process. Actors may update in different directions or may simply continue not to update for quite some time. On the other hand, the evidence seems to contradict some of the results obtained in laboratory experiments. For instance, we do not so far any clear evidence that when negotiators hold beliefs they tend to ignore information that disconfirms those beliefs, as shown in work by Lord et al. (1979) or Ross and Anderson (1982). Similarly, we cannot affirm that negotiators exhibit cognitive closure, as a way to simplify their negotiation behavior (De Dreu et al. 1999, Kruglanski and Webster 1996). It thus appears that our work may differ quite significantly from prior work using simulated worlds, and yields trends quite in line with some formal, abstract models. To see whether this is indeed more than an artefact, we now turn to a discussion of learning patterns.

\footnotetext{
${ }^{13}$ We could use data from exercise 1 because the questionnaire did not include the relevant questions.
} 


\section{Information transmission and patterns of change}

The data, presented above, suggests that the convergence process is on the one hand not smooth, and on the other hand is sometimes hard to discern. The aim of this section is to uncover factors that can explain specific patterns of learning or the absence of learning. We structure our discussion along factors that have been extensively assumed or researched in other work. We begin with the relevance of signals, then turn to the imprint of initial expectations, continue with potential problems of transparency, the influence of biases, of country specific features and lastly discuss the importance of truthfulness.

\section{1) A Signalling Game?}

Although we have not found explicit evidence that actors have as sophisticated an interpretative attitude towards signals as assumed in most theoretical models of bargaining, we can confidently argue, on the basis of our qualitative observations, that the exercises have features of signalling games, in which actors send pieces of information about their "type" to negotiating partners and in which partners show a capacity to decipher the meaning of signals. To give one specific example, in exercise $\mathrm{n}^{\circ} 4$ for instance, during the preliminary discussions (before the starting of bilateral meetings), Alba proposed a formula approach that implicitly aimed at getting a drastic reduction in Tristat's agricultural tariff peaks, as high as $120 \%$ for one product. This strong "signal" was well understood by Tristat's Ambassador, who declared to his team: "Our position in agriculture is going to be extremely uncomfortable".

As assumed in formal models, the interpretation of signals is a difficult, contingent exercise in particular when countries resort to bluffing tactics. This is the 
case, for example, of Alba vis-à-vis Medatia in exercise $n^{\circ} 1$. On the second day of negotiations, Alba initiated a new tactics by asking all tariffs to be bound at the applied rate. Alba's Ambassador was well aware that this request was way beyond what Alba's Cabinet orders instructed him to accept from Medatia, so we can safely claim that the request was a bluff. Interestingly, Medatia's reaction was not to change anything in its assessment of the zone of agreement but it did change its evaluation of Alba's knowledge about its own bottom lines.

As an evidence of the difficulty to signal, we observed, in some cases, inconsistencies between tactical moves and the related signals. In exercise $n^{\circ} 3$, for instance, Alba issued a very generous offer of tariff reductions to Medatia but the Ambassador, due to poor negotiating skills, was not able to send a consistent signal of generosity. ${ }^{14}$ Alba's Ambassador's had a very negative impact on Medatia's Ambassador's assessment of Alba. During the interview that followed the episode, he pointed at Alba as the least cooperative partner (while on the first day Alba was the most cooperative partner for Medatia). He also evaluated that a zone of agreement between Medatia and Alba no longer existed. Finally, he gave Alba a "2" on the truthfulness scale, while on the first day Alba had scored 3. The situation improved significantly on the last day of negotiations. Medatia's Ambassador estimated that there was again a zone of agreement with Alba; he also gave Alba a "4" on the truthfulness scale, which is the highest score given by him during the three daily interviews.

This example is, in our opinion, a good illustration of the complexity of signals. In particular, it is hard to determine for negotiators what among features of

\footnotetext{
${ }^{14}$ Of course, the evaluation of generosity is subjective. In this instance, Alba offered reductions on fifteen products out of a total of 30 . Moreover, this was an unconditional offer, also in the sense that it
} 
the interchange between parties are relevant signals. To put it into the context of game-theoretic models, how can negotiators determine a "revealing" signal? Our observations so far are not sufficient for elaboration on that topic but it is clear that signals are rarely clear enough. A particular offer or request needs to be carefully communicated and explained so as to have the expected effect or answer on the receiver.

\section{2) Importance of initial beliefs and expectations?}

A puzzling aspect of the evidence presented in Table 1 and 2 above is the existence of a kind of decrease of knowledge between day 1 and day 2. This raises, in our opinion, the question of the initial beliefs of negotiators. It may well be that they start the process being too optimistic about their knowledge and that they then quickly come down to earth, so to speak, when they receive the first proposals or demands from other teams.

We have some clear evidence of optimism at the beginning of the process. When asked "Are you satisfied with the advancement of negotiations up to now?" on the first day, Ambassadors generally express a moderate or high level of satisfaction even in cases where bilateral meetings have not yet formally begun, and the teams are still involved in the process of elaborating their "offers" and "requests" and/or agreeing on negotiating modalities. ${ }^{15}$ Similarly, few Ambassadors replied negatively

\footnotetext{
did not respond to any request by Medatia. Third, it was very close to the offer contained in the final bilateral agreement, indicating its closeness to Alba's bottom line.

${ }^{15}$ The level of satisfaction ranges from 1 (least satisfied) to 5 (fully satisfied). On the first day, there was one 5 ( 6.25 per cent of the total of 16 answers), five 4 ( 25 per cent), seven 3 ( 43.75 per cent), two 2 (12.5 per cent) and just one 1 (6.25 per cent). Interestingly, the lowest scores were recorded in the exercise $n^{\circ} 3$, which ended with full agreement, well before the deadline.
} 
on the first day to the question of the existence of a zone of agreement, ${ }^{16}$ even though it is very likely that very few of them (if any) had a clear idea of the rightful answer at this point of the negotiation.

Turning to the explanation for such optimism, overconfidence might be at work. As some previous work has shown, negotiators tend to overestimate their ability to control uncontrollable events (Crocker 1982, Miller and Ross 1975). In this line, it has been argued that a reason parties cooperate in one-shot prisoner dilemma games is the illusion that their own cooperation will create cooperation in the other party (Morris et al. 1998, Shafir and Tversky 1992).

However, it is also possible that the large number of positive numbers is a consequence of ambassadors' expectations that the TNSE is construed in a way as to allow for bargaining zones (after all, the practice of bargaining is the goal of the simulation).

\section{3) Illusion of transparency?}

Whereas the simulations reveal a convergence process, they also reveal, through the large number of questions unanswered, that actors have anything but a clear perception of others. Prior work using laboratory experiments points, as a potential explanation, to possible bias in the estimation by any negotiator of other negotiators' knowledge. For instance, Vorauer and Claude (1998), measuring negotiators' perceived transparency with regard to their objectives, find that negotiators overestimate the transparency of their objectives, in particular when those goals have a high salience and when they can easily resort to communication. Another study by

\footnotetext{
${ }^{16} \mathrm{n}^{\circ} 1: 2$ yes, 6 do not know, 1 no (3 no answer); ${ }^{\circ} 2: 5$ yes, 0 no, 7 do not know; ${ }^{\circ} 3: 6$ yes, 4 do not
} 
Van Boven, Gilovich, and Medvec (2003) finds that negotiators who were told to conceal their preferences were overestimating their partners' ability to detect these preferences but did only do so in the end of the negotiation after 30min (note the parallel to our research on the perception of knowledge of reservation values that negotiators also try to conceal).

As regards the reasons for these biases, these pieces of research highlight that negotiators' overestimation of their partners' ability to discern their preferences stems from both a curse of knowledge (tendency to project one's knowledge onto others / overestimating the availability of whatever they themselves know) and an illusion of transparency (overestimating the extent to which their own characteristics and goals "leak out" and are known by others).

Put into the perspective of the TNSE, the above cited research would indicate that negotiators' perception of their opponents knowledge of their resistance point is biased towards overestimating that knowledge and even more so as time passes. Looking at evidence from the four exercises, we clearly see an increasing trend in the evolution of the estimations of opponents' perceptions of one's own knowledge. In 15 cases out of 48 , estimations increase in contrast to only 3 cases of decrease. But we also observed 11 cases without any change and 19 cases with missing or incomplete responses. Furthermore, the bias towards overestimation is not linear: there seems to be a dip on the second day with 11 cases of decrease between day 1 and day 2 .

Going back to the data presented in Table 2 above, we do not see much evidence of the illusion of transparency either. Counting the number of times that the perception of knowledge of one party coincides with the estimation of that knowledge by the other party, we find a total of 36 cases of matching, 38 invalid answers (where 
at least one party did not answer), 24 cases where the latter party overestimates the knowledge of the first party and 46 cases where that knowledge is underestimated. The conclusion that we can draw is that the party who estimates its knowledge of the other party's maximum concessions claims to have a better knowledge than the other party would think that the former party actually has almost twice as often than the latter party perceives his resistance point to be more transparent than the former party thinks it is.

This seems to go in opposite direction from the bias of an illusion of transparency. ${ }^{17}$ The evidence may instead confirm previous work that reveals that people tend to perceive themselves as being better than others on desirable attributes and have unrealistically positive self-evaluations ((Gabriel et al. 1994, Messick et al. 1985, Svenson 1981, Brown 1986). In our view, the ability to find out and process information on opponents is such a desirable attribute. Indeed, when one asks an ambassador whether he has found out what the other party's resistance point is, we should expect him to be more likely to boost his skills rather than to admit that he was unable to find out this information.

${ }^{17}$ To further test this interesting result we would need, however, to include new, and more specific, questions in the interviews. For instance we could ask ambassadors to estimate the 5(?) most and least important sectors/products of their opponents (to test if there is information exchange on preferences) and then give an estimation for their opponents' maximumconcessions in these sectors (more difficult to compare). This would be compared with the cabinet instructions and maybe partly with that party's own perception to find out the accuracy of negotiator's judgment. Finally, negotiators would also be asked to give an estimation of the correctness of their judgments on the opponent's preferences and resistance point. The perceived knowledge would consequently be compared to actual knowledge to find out if negotiators are indeed overconfident of their judgments. Similarly one could test the illusion of transparency. Another interesting question would be to ask negotiators if they are aware that their opponent is overestimating his knowledge on their preferences and maximum concessions. However, a question asking the negotiator to estimate the perceived knowledge of the second negotiator on the preferences and resistance point of the first instead of estimating his actual knowledge could make negotiators realise the answer implicitly (overconfidence). 


\section{4) Too quick or oversimplified tactical choices?}

Pretty fixed visions of what the others can give and what they should do may be a serious obstacle to learning. As some literature has shown, individuals sometimes have the tendency to ignore the cognitions of others and the contingent process of negotiation (Samuelson and Bazerman 1985; Caroll et al. 1988). An example of such a behavior in the TNSE is to adopt as a behavior rule: "I am strictly following Cabinet Orders, without granting any further concession". Normally, it takes some time to negotiators to fully understand that Cabinet Orders are mutually incompatible. Some

of them simply do not come to this understanding, thus making the process fail. ${ }^{18}$ Most of the times, this happens only to isolated participants. For example, Tristat' counsellor in exercise $n^{\circ} 4$ had more than an argument with his Ambassador and other teammates about the opportunity to include the agricultural sector in any bilateral deal. Interpreting the Cabinet Orders as a strict rule, he preferred failure in negotiations to giving up.

To simplify the game, participants could use other rules of thumb. One would be to search for an agreement at any cost, having understood that it was the purpose of the exercise and that reaching an agreement was the outcome expected by the Secretariat. This would have the effect of bwering a country's BATNA. Countries also use their knowledge of the power relations that exist among themselves: they know that they have different BATNAs, and that some of them are more in need of an agreement (either in the tariff negotiation, the non-tariff negotiation, or both) than others. We can see from the debriefing questionnaire given in exercises $n^{\circ} 3$ and 4 that most participants can think of an answer when they are asked: "Regarding tariff negotiations, which do you think was the country that was most in need of striking a 
bilateral agreement with your country?"19. The same question on non-tariff negotiations yielded similar results ${ }^{20}$. This is all the more remarkable that each team has a number of its members involved either in the tariff negotiations, or in the nontariff negotiation. This means that experts in tariffs, for instance, are unlikely to know much about what is happening in the non-tariff negotiations, and are therefore not expected to be able to reply to every question in the debriefing questionnaire.

Such a behavior would imply that negotiators do not rely on the details of offers and requests to elaborate their strategy and tactics: they know already the "rules of the game" and who will give up most in the end. We observed it in the case of Alba's Ambassador, in exercise $\mathrm{n}^{\circ} 1$. He understood very well the strengths and weaknesses of the others' positions, and after issuing his last offer to Tristat he advised his delegation not to meet members from Tristat's delegation, so that Tristat would have to come to Alba and not the other way round. Alba's ambassador, who was a highly skilled negotiator, knew that Tristat needed the agreement more than Alba, who had a better BATNA. He plainly told Tristat's Ambassador that "If we cannot sign, we will not sign", pushing Tristat to accept quickly the last offer. Obviously this rule of thumb can only be the matter of skilled and experienced negotiators (who have a good experiences of the dynamics of negotiations) like Alba's Ambassador in exercise $n^{\circ} 1$. Ignoring signals coming from others may not an obstacle to learning if those signals do not reveal anything new.

\footnotetext{
18 This happened in a TNSE we did not observe, except for the debriefing session, in which the problem emerged.

${ }^{19}$ Exercise ${ }^{\circ} 2: 11$ answers and 4 no answers; exercise ${ }^{\circ} 3: 13$ answers and 5 no answers.

20 "Regarding non-tariff negotiations, which do you think was the country that was most in need of striking a multilateral agreement? Why?" exercise $n^{\circ}$ 2: 9answers and 6 no answers; exercise $n^{\circ} 3: 12$ answers and 6 no answers.
} 


\section{5) Self-serving bias ?}

The absence of a bias related to previous negotiating "rounds" does not rule out the possibility that actors develop one or more biases during the process. Due to the short time-span in which the exercise takes place, this phenomenon can best be observed $e x$ post, looking at the results of the debriefing questionnaire. The purpose of the debriefing questionnaire was to enable the participants to reflect on the exercise that had just been completed and to make them share their perception of the main features of the game, namely its conformity with reality (or lack thereof), the negotiating strategies that were pursued, and the major problems that slowed down the reaching of an agreement.

The results show that participants have a very different assessment of the relevance of a possible problem depending on whether it originates from their team or from others. When asked "Do you think lack of flexibility from other countries was a major problem in the negotiating process?" the answers are overwhelmingly positive. ${ }^{21}$ On the other hand, when asked "Do you think lack of flexibility from your own Minister was a major problem in the negotiating process?" the responses are as overwhelmingly negative. ${ }^{22}$ We find parallel results when we compare two other potential problems that mirror each other: a majority of participants found that "unrealistic initial requests from other countries" happened to be a major problem in the negotiation process, while "unrealistic ministerial instructions for your team" were not. Individuals tend to blame others' personal traits (e.g. lack of flexibility) rather than situational characteristics for failure.

\footnotetext{
${ }^{21} \mathrm{n}^{\circ} 2: 14$ yes, 1 no; $\mathrm{n}^{\circ} 3: 16$ yes, 2 no; $n^{\circ} 4: 9$ yes, 4 no ( 1 No answer).

${ }^{22} \mathrm{n}^{\circ} 2$ : 1 yes, 12 no (2 No answer); $\mathrm{n}^{\circ} 3$ : 0 yes, 16 no; $\mathrm{n}^{\circ} 4: 2$ yes, 12 no.
} 
These results reflect a quite strong self-serving bias, i.e. a natural tendency to take credit for success but blame the situation (or the others) for failure. The participants attribute the difficulties encountered in the course of the negotiations not to their own gaps, but to the others, even though it seems quite absurd to believe that only the other Ministers' toughness slowed down the negotiations, and not one's own. This bias is, in the case of teams, reinforced by the common tendency to favor one's in-group by opposition to the out-group. More specifically, the constitution of teams, however arbitrary, has the effect of developing cohesion with members of the same team ("in-group") and prejudice towards the other teams ("out-group"). ${ }^{23}$ This tendency develops with time, as the different teams get to know (and confront) each other. In exercise $n^{\circ} 4$, we asked parallel questions in the debriefing questionnaire (i.e. at the end of the exercise) on the performance of the teams ${ }^{24}$ : more people invoked "lack of skill of other negotiating teams" as a problem in the negotiation than "poor performance of your own negotiating team" 25 .

Linda Babcock and George Loewenstein (1997) have further elaborated on the self-serving bias by combining it to the notion of fairness; according to them, parties to a negotiation tend to confuse what is fair and what benefits them; in other words, they assess fairness in a way that serves their interests. As a matter of fact, we observe such reactions in the TNSEs, following two lines: one reflecting the type of country, and the other reflecting individual, sector specific interests.

The four countries of the TNSE represent the whole of world trade. In order to be closer to reality, they are given different levels of development: Alba and Tristat

\footnotetext{
${ }^{23}$ See Muzapher Sherif's (1967) experiment on group competition.

${ }^{24}$ The question on "lack of skill of other negotiating teams" did not exist in the questionnaires of the three previous exercises.
} 
are developed countries, while Medatia and Vanin are developing countries. Even though the exercise is structured not to favor any particular country or group of countries, participants tend to think that developing countries should be granted special treatment due to their socio-economic condition. We observed that very often, in the course of the negotiations, developing countries were trying to explain to their developed partners that exchanging one concession for one concession was not a fair deal because a developing country would lose much more than a developed country. In other words, "one concession" did not have the same weight for the two types of countries, and developing countries should therefore be given more than they themselves give. Developed countries, on the other hand, were willing to follow strictly their Cabinet orders and not give any extra benefit to developing countries based on their condition. Not only did they think their behavior was fair, they also considered that the simple fact of negotiating with developing countries was a demonstration of good will. This is all the more striking that some participants coming from developing countries tend to "overplay" in the sense that they are more demanding towards developing countries than actual developed countries would be (this was for instance the case of Alba's Ambassador in TNSE $n^{\circ} 3$ ).

The existence of individual (or sector specific) self-serving bias can also be observed in the TNSE. Countries have different "sensitive" sectors, i.e., protected sectors in which Cabinet Orders mandate to limit concessions, because of domestic concerns. The most recurrent example can be found in negotiations between Alba and Tristat over the four TNSE we observed. These two countries are both developed ones, so that considerations of fairness cannot be related to a development gap. Alba's

\footnotetext{
${ }^{25}$ To the question: "Do you think the following were major problems in the negotiating process?" we got the following results for "Poor performance of your own negotiating team": 1 yes, 11 no and 1 no answer; for "Lack of skill of other negotiating teams", we got 5 yes, 8 no and 1 no answer.
} 
most sensitive sector is textiles whereas Tristat's is agriculture. The major difference between the two countries is that the former applies much lower tariffs in the textiles sector than the latter in the agricultural one. This means that the same percentage reduction would bring down Tristat's agricultural tariffs more dramatically than Alba's textiles tariff. ${ }^{26}$ Any offer of reciprocity in tariff cuts is usually presented as fair and balanced by Alba, but is perceived as unfair by Tristat. This happened, for example, in exercise $n^{\circ} 4$. At first, Tristat tried to exclude agriculture from the talks; later, when it understood that there would not be any deal if agriculture were to be excluded, it argued in favor of special and differential treatment based on the notion of multifunctionality.

\section{6) Country characteristics and individual learning}

Our discussion of self-serving bias suggests some differences across countries. Do we find additional evidence of variations in negotiation behavior that may come from country characteristics? Generally speaking, first, it is difficult to infer a particular pattern in the answers to the question of the cooperativeness of countries. Asked about the most and least cooperative countries, some ambassadors name the same most or least cooperative country three days in a row, while some others change their assessment every day. In exercise $\mathrm{n}^{\circ} 2$, for instance, Medatia and Tristat cite consistently Alba as "most cooperative" during the three days of the TNSE, but in the exercise $n^{\circ} 3$ they never mention twice the same country. When countries change their mind and name a different country from the one they had the day before, they do mot do it simultaneously, and they rarely change for the same country. This means that the

\footnotetext{
${ }^{26}$ For example, if both Tristat and Alba would cut their tariff peak by 30 per cent, Tristat's tariff on dairy products would be reduced from 120 to 84 per cent, while Alba's tariff on t-shirts would only be
} 
assessment of cooperativeness is not multilateral at all: it depends on how the bilateral meetings go. A turbulent bilateral with one country is often sufficient to have its name mentioned in the "least cooperative" category.

Table 5: Number of mentions as most or least cooperative country

\begin{tabular}{|l|l|l|}
\hline & $\begin{array}{l}\text { Most cooperative } \\
(\mathrm{Max}=36)\end{array}$ & $\begin{array}{l}\text { Least cooperative } \\
(\mathrm{Max}=36)\end{array}$ \\
\hline Alba & 17 & 3 \\
\hline Medatia & 10 & 7 \\
\hline Tristat & 11 & 19 \\
\hline Vanin & 9 & 11 \\
\hline
\end{tabular}

Note: Each country can be named at most three times per day by its partners as the most or least cooperative, yielding a maximum number of citations of 36 .

But over the four TNSEs, however, a slight pattern seems to appear as can be seen in Table 5. Alba is cited 17 times as the most cooperative country over a maximum number of 36, while others are cited between 9 and 11 times only. For the least cooperative country, it is Tristat who is cited more often than the other countries (19 times over a maximum of 36). One reason could be the fact that Alba is the most developed of the developed countries, and it might be easier for them (rather than for developing countries) to grant generous concessions. Another element that has to be taken into account is the content of the Cabinet orders: a country could be consistently cited as most cooperative if it had more lenient orders, making it less likely that it is going to struggle hard in the negotiations and be very demanding. Tristat, as we have argued, has a difficult negotiating position indeed in agriculture because of very high tariff peaks (up to $120 \%$ ); its concern even with the with decimals is a sure recipe for making other teams upset. ${ }^{27}$

reduced from 20 to 14 per cent.

${ }^{27}$ For example, in exercise $n^{\circ} 1$ the relationship between Tristat and Vanin were empoisoned by this factor. We report an excerpt from the bilateral meeting on Wednesday afternoon of the last afternoon: Vanin: "We have to think of other strategies because this is not working. You are just talking about decimals. We are thinking of withdrawing our position on subsidies negotiations as well. We have been very serious, we have made efforts. But $0.6,0.4 \%$..."

Tristat: "But it is important!" 
However, one should take these results carefully. In fact, in exercise $n^{\circ} 3$, accounting for a relevant part of the cases where Tristat is listed as least cooperative one, Tristat's team was significantly underskilled in comparison to the other teams (not even being able to issue offers and requests, and thus to organize bilateral meetings). It is therefore not surprising that other teams constantly pointed at Tristat. More observations would be needed to detect any recurrent pattern.

Also linked to the way in which Ambassadors evaluate the cooperativeness of other countries, is the issue of the personality of the negotiators. It is difficult, for instance, not to relate the fact that Alba was cited 6 times over 11 in the exercise $\mathrm{n}^{\circ} 1^{28}$ and only 2 times over 12 in the exercise $n^{\circ} 3^{29}$ to the personalities of Alba's Ambassadors who conducted these particular negotiations. In exercise $n^{\circ} 1$, he was a very experienced, articulate and skilled diplomat, while in $n^{\circ} 3$ he was a more difficult character, who had a contemptuous and derogatory attitude towards other negotiators and in particular towards developing countries. On this aspect again the TNSE appears as a realistic simulation: clash of personalities can undermine negotiations and threaten the obtaining of a final agreement.

So, in sum, even though there is here some additional evidence that country features may influence systematically individual behavior, we can hardly infer that this evidence is overwhelming.

\footnotetext{
$\mathrm{V}$ : "No, you are playing with these percentages. This is meaningless"

$\mathrm{T}$ : "It is not a point of reducing. It is the relative amount of reduction from base rate"

V: "It is meaningless"

T: "It is meaningless for your country, but it is meaningful to mine. We are not going any further".

${ }^{28}$ In exercise $n^{\circ} 1$, Alba was never cited as least cooperative country.

${ }^{29}$ In exercise $n^{\circ} 3$, Alba was cited 2 times over 8 as least cooperative country.
} 


\section{7) Truthfulness and learning}

The importance of truthfulness is the last issue that we would like to discuss in this paper. Clearly, truthfulness should facilitate information exchange and thus fasten the convergence process (Thompson 1991). Even though negotiators are usually not naive enough to believe that the expression: "this is the maximum I can give" is always to be taken at face value, it usually helps a negotiation move forward if they know that the other person is not making abusive demands. From that perspective, Ambassadors were asked every day the following question: "How would you evaluate the truthfulness of the others' claims?" The results show interesting trends. First, a large number of answers show stability in the assessment of others' truthfulness (14 answers out of 36). Second, we find an upward trend in the evaluation of others' truthfulness (9 answers out of 36) and almost no decreasing trend (3/36). In, the remaining ten cases Ambassadors were either not able or not willing to tell anything.

The upward trend is therefore not dominant, contrary to what was found on the question on knowledge. The emphasis on the stability of the perception of others' truthfulness seems to indicate that the trust building phenomenon is less salient than the building of knowledge. It seems like once a country has an idea of how much someone's claims can be trusted, it sticks to this opinion and this opinion is quite resistant to change (i.e. it is not so much updated with the incoming of new information). One reason could be that trust has more to do with issues of personality than knowledge. In other words, evaluation of truthfulness may have more to do with the personality (friendly or deceptive) of negotiators as perceived on the first day than with the subsequent development of the negotiations.

It is interesting to see whether there is a correlation between countries' assessment of each other cooperativeness, and their evaluation of the level of 
truthfulness of their claims. For the exercises $n^{\circ} 2$ and 3 , we observed that the two questions entail similar answers: the country that is deemed as the most cooperative is always the one that scores highest on the question "How would you evaluate the truthfulness of others' claims?" ${ }^{30}$ Conversely, the country that is said to be the least cooperative is always the one with the lowest score in terms of truthfulness. This happens in $100 \%$ of the 33 instances observed in these two exercises (18 for most cooperative and 15 for least cooperative). Results are different in exercise no 4: in 6 instances over a total of 24 , we observed discrepancy on the relation "most cooperative" - "most truthful" or the opposite "least cooperative" - "least truthful." However, if we look closer at the discrepant results of exercise $n^{\circ} 4$, we find out that the truthfulness scores of the most truthful country and of the most cooperative country (that was, in other exercises, also the most truthful) are usually quite close: we note a difference of one point in 5 cases over a total of 6 , and two points in the last case. Overall, there seems therefore to be a clear correlation between the level of truthfulness and the level of cooperativeness. We need more observations to strengthen that point, but it seems that Ambassadors tend not to differentiate between the two concepts.

\section{Conclusion}

Information exchange is a central feature of international negotiations. As a large body of literature from different fields and using different research methods has showed, information transmission and interpretation can have an important influence on the bargaining outcome. Yet, there are still many gaps in our understanding of the uses individuals make of information, particularly of changing information. Formal models assume some information processing rules, descriptive studies tend to come

\footnotetext{
${ }^{30}$ Or, if some countries share the same highest score, one of them.
} 
up with post hoc claims, and previous laboratory experiments seriously question learning. Our paper brings some new evidence using simulation exercises designed to be close to real world negotiations (both in time and complexity) and involving individuals with either prior experience in trade negotiations or with likely future involvement in such negotiations. Furthermore, simulations involve participants from the developing world (or countries in transition), in contrast to most existing studies so far.

The first major finding of our work is that there is a consistent pattern of convergence of perception and knowledge among negotiators. Individuals revise their initial beliefs and expectations as the negotiation proceeds. In short, individuals show what we could call a learning attitude. On that account, formal models of the negotiation process, in particular signalling models, do seem to make valid assumptions. And the experimental literature may look too pessimistic.

The paper brings home a second set of more specific findings as regards patterns or dynamics of information processing by individuals. Overall, these findings reveal that learning is difficult and can be derailed by a host of factors. Signals are both difficult to define and interpret especially when bluffing is a recurrent tactic and truthfulness difficult to establish. Overconfidence seems to be at work both with regards to the ability to uncover others' characteristics and constraints and with regard to the ability to reach an agreement. Self-serving biases and some other forms of cognitive closure affect the narrowing of differences between the bargaining positions. Different country characteristics may also interfere, although to a lesser extent.

These findings may have important practical relevance. To begin with, our observations reveal that good signalling should entail careful communication. To 
simply make an offer or request and hope that the other ones will interpret way in the desired way is too optimistic a view about the negotiation process. There are hardly obvious signals. Next, overconfidence should not be encouraged. If one could think that overconfidence may impress the other side, it is in fact more likely to yield a deadlock than any advantageous agreement. From this perspective, easy recipes from best-selling literature on bargaining may prove quite counterproductive. Similarly, self-serving biases undermine serious efforts toward mutual understanding. Discussions around the notion of fairness regularly show how an exchange between self-serving oriented individuals can become sterile. Lastly, regular encounters between individuals should mostly aim at establishing truthfulness as a critical facilitator to learning and smoother negotiation processes. Clearly, on that account, it may be easier to negotiate among a small group of Geneva-based diplomats than among elected politicians who meet occasionally.

We would like to end with some caveats and some avenues for further work. The evidence we present in this paper is based upon a limited number of individuals (roughly 100) who did a simulation exercise with a specific design (GATT/WTO) and whom we observed mostly on tariffs negotiations. One clear drawback of the chosen design is that we were not able to gain much about learning in multilateral settings. In a GATT/WTO tariff world, bilateral meetings drive the process and thus learning mostly follows the bilateral route. A last, and important, caveat relates to the impossibility to contrast our findings with exercises done by participants from the developed world. The fact that our findings differ in several respects from results obtained in laboratory experiments in developed countries' universities with students mostly coming from the developed world may hint at possible interesting variations. 
There are, however, too many potential differences between our sample of students and those of the relevant literature to go beyond risky conjectures at that stage.

The caveats clearly outline the three most important avenues for future work. First, we aim at expanding the number of observations using the same design and same data collection methods. This will allow us more specific analysis of individual variations. Second, we would like to run the same experiment with participants from the developed world. Third, we will try to run a different experiment with a more multilateral flavor. Clearly the last two extensions raise difficult challenges but ultimately they will be the only way to test the robustness of the general trends reported here. 


\section{References}

Babcock, L. and G. Loewenstein (1997). Explaining Bargaining Impasses: The Role of Self-Serving Biases. Journal of Economic Perspectives 11: 109-126.

Bazerman, M. H., et al. (1985). Integrative Bargaining in a Competitive Market. Organizational Behavior and Human Performance 34: 294-313.

Brown, J. D. (1986). Evaluations of Self and Others: Self-Enhancement Biases in Social Judgment. Social Cognition 4: 353-376.

Bueno de Mesquita, B. (1990). Multilateral Negotiations: A Spatial Analysis of the Arab-Israeli Dispute. International Organization 44: 317-340.

Caroll, J. S., et al. (1988). Negotiator Cognitions: A Descriptive Approach to Negotiatiors' Understanding of Their Opponents. Organizational Behavior and Human Decision Processes 41: 352-370.

Crawford, V. P. (1995). Adaptive Dynamics in Coordination Games. Econometrica 63: 103-143.

Crawford, V. P. and H. Haller (1990). Learning How to Cooperate: Optimal Play in Repeated Coordination Games. Econometrica 58: 571-595.

Crocker, J. (1982). Biased Questions in Judgment of Covariation Studies. Personality and Social Psychology Bulletin 8: 214-220.

De Dreu, C. K. W., et al. (1999). On the Seizing and Freezing of Negotiator Inferences: Need for Cognitive Closure Moderates the Use of Heuristics in Negotiation. Personality and Social Psychology Bulletin 25: 348-362.

Druckman, D. (1977). Social-Psychological Approaches to the Study of Negotiation. In D. Druckman. Negotiations. Social-Psychological Perspectives. Beverly Hills: Sage.

Dupont, C. (1994a). Domestic Politics and International Negotiations: A Sequential Bargaining Model. In P. Allan and C. Schmidt. Game Theory and International Relations. Cheltam: Elgar Publisher.

Dupont, C. (1994b). Domestic Politics, Information and International Bargaining. Comparative Models of Strategic Behavior in Non-Crisis Negotiations: Graduate Institute of International Studies, Geneva.

Dupont, C. and P. Sciarini (1995). La négociation agricole Etats-Unis-Communauté Européenne dans l'Uruguay Round: une difficile convergence. Revue suisse de science politique 1: 305-352.

Dupont, C. and P. Sciarini (1998). "Seeds of Conflict". Graduate Institute of International Studies, Geneva and European University Institute, Florence. 
Foster, D. P. and H. P. Young (2003). Learning Nash Equilibrium: The Santa Fe Institute Working Paper.

Gabriel, M. T., et al. (1994). Narcissistic Illusions in Self-Evaluation of Intelligence and Attractiveness. Journal of Personality 62: 143-155.

Iida, K. (1993). When and How Do Domestic Constraints Matter? Journal of Conflict Resolution 37: 403-426.

Iklé, F. C. (1964). How Nations Negotiate. New York: Harper and Row.

Kruglanski, A. W. and D. M. Webster (1996). Motivated Closing of the Mind: "Seizing and Freezing". Psychological Review 103: 263-283.

Lohmann, S. (1997). Linkage Politics. Journal of Conflict Resolution 41: 38-67.

Lord, C. G., et al. (1979). Biased Assimilation and Attitude Polarization: The Effects of Prior Theories on Subsequently Considered Evidence. Journal of Personality and Social Psychology 37: 2098-2109.

Messick, D. M., et al. (1985). Why We Are Fairer Than Others. Journal of Experimental Social Psychology 21: 480-500.

Miller, D. T. and M. Ross (1975). Self-Serving Biases in the Attribution of Causality: Fact or Fiction? Psychological Bulletin 82: 213-225.

Milner, H. V. (1997). Interests, Institutions, and Information. Princeton: Princeton University Press.

Milner, H. V. and B. P. Rosendorff (1997). Democratic Politics and International Trade Negotiations. Journal of Conflict Resolution 41: 117-146.

Mo, J. (1994). The Logic of Two-Level Games with Endogenous Domestic Coalitions. Journal of Conflict Resolution 38: 402-422.

Mo, J. (1995). Domestic Institutions and International Bargaining: The Role of Agent Veto in Two-Level Games. American Political Science Review 89: 914-924.

Morgan, T. C. (1994). Untying the Knot of War. A Bargaining Theory of International Crises. Ann Arbor: University of Michigan Press.

Morris, M. W., et al. (1998). Distinguishing Sources of Cooperation in the OneRound Prisoners' Dilemma: Evidence for cooperative decisions based on the illusion of control. Journal of Experimental Social Psychology 34: 494-512.

Neale, M. A. and M. H. Bazerman (1991). Cognition and Rationality in Negotiation. New York: Free Press. 
Neale, M. A., et al. (1987). The Framing of Negotiations: Contextual Versus Task Frames. Organizational Behavior and Human Decision Processes 39: 228241.

Neale, M. A. and G. Northcraft (1986). Experts, Amateurs, and Refrigerators: Comparing Expert and Amateur Negotiators in a Novel Task. Organizational Behavior and Human Decision Processes 38: 305-317.

Odell, J. S. (2000). Negotiating the World Economy. Ithaca: Cornell University Press.

Pahre, R. (1997). Endogenous Domestic Institutions in Two-Level Games and Parliamentary Oversight of the European Union. Journal of Conflict Resolution 41: 147-174.

Putnam, R. D. (1988). Diplomacy and Domestic Politics: The Logic of Two-Level Games. International Organization 42: 427-460.

Raiffa, H. (1982). The Art and Science of Negotiation. Cambridge: Belknap Press of Harvard University Press.

Ross, L. and C. A. Anderson 1982. Shortcomings in the Attribution Process: On the Origins and maintenance of erroneous social assessments. In D. Kahnemanet al. Judgement Under Uncertainty: Heuristics and Biases. Cambridge: Cambridge University Press.

Roth, A. E. (1988). Laboratory Experimentation in Economics: A Methodological Overview. Economic Journal 98: 974-1031.

Roth, A. E. and J. K. Murnighan (1982). The Role of Information in Bargaining: An Experimental Study. Econometrica 50: 1123-1142.

Rubin, J. A. and B. R. Brown (1975). The Social Psychology of Bargaining and Negotiations. New York: Academic Press.

Samuelson, W. F. and M. H. Bazerman 1985. The Winner's Curse in Bilateral Negotiations. In V. Smith. Research in Experimental Economics. Greenwich, CT: JAI Press.

Schelling, T. C. (1960). The Strategy of Conflict. Cambridge: Harvard University Press.

Shafir, E. and A. Tversky (1992). Thinking Through Uncertainty: Nonconsequential reasoning and choice. Cognitive Psychology 24: 449-474.

Sherif, M. (1967). Group Conflict and Cooperation. London: Routledge.

Simon, H. (1955). A Behavioral Model of Rational Choice. Quarterly Journal of Economics 69: 99-108. 
Simon, H. A. (1959). Theories of Decision-Making in Economics and Behavioral Science. American Economic Review 49: 253-283.

Svenson, O. (1981). Are We Less Risky and More Skillful than Our Fellow Drivers. Acta Psychologica 47: 143-151.

Thompson, L. L. (1990). The Influence of Experience on Negotiation Performance. Journal of Experimental Social Psychology 26: 528-544.

Thompson, L. L. (1991). Information Exchange in Negotiation. Journal of Experimental Social Psychology 27: 161-179.

Van Boven, L., et al. (2003). The Illusion of Transparency in Negotiations. Negotiation Journal 19: 117-131.

van Huyck, J. B., et al. (1990). Tacit Coordination Games, Strategic Uncertainty, and Coordination Failure. American Economic Review 80: 234-248.

van Huyck, J. B., et al. (1991). Strategic Uncertainty, Equilibrium Selection Principles, and Coordination Failure in Average Opinion Games. Quarterly Journal of Economics 106: 885-910.

van Huyck, J. B., et al. (1997). On the Origin of Convention: Evidence from Coordination Games. Economic Journal 107: 576-596.

Vorauer, J. D. and S. Claude (1998). Perceived Versus Actual Transparency of Goals in Negotiation. Personality and Social Psychology Bulletin 24: 371-385.

Young, H. P. (1998). Individual Strategy and Social Structure. Princeton: Princeton University Press. 
1. Are you satisfied with the state of negotiations up to now ?

least satisfied

(1) partially

(2) moderately

(3) fairly

(4) fully satisfied

(5)

Why ?

2.1. Could you explain your negotiating strategy in a few words?

2.2. Have you changed your strategy since yesterday? If yes, how and why?

3.1. Which country do you find the most cooperative?

Alba Medatia Tristat Vanin

Why ?

3.2. Which country do you find the least cooperative?

$\begin{array}{lll}\text { Alba } & \text { Medatia } & \text { Tristat }\end{array}$

Why?

4.1. In negotiations with Alba, have you already gone down to your maximum concessions on any product/sector? If yes, which of them?

4.2. In negotiations with Medatia, have you already gone down to your maximum concessions on any product/sector? If yes, which of them? 
4.3. In negotiations with Tristat, have you already gone down to your maximum concessions on any product/sector? If yes, which of them?

4.4. In negotiations with Vanin, have you already gone down to your maximum concessions on any product/sector? If yes, which of them?

5. On a 1 to 5 scale, 5 being the maximun, how would you evaluate your knowledge of the maximum concessions that $\mathrm{X}$ can make?

Alba:
(1)
(2)
(3)
(4)

(5)

Medatia:
(1)
(2)
(3)
(4)

Tristat:
(1)
(2)
(3)
(4)

Vanin:

(1) (2)

(3)

(4)

6. On a 1 to 5 scale, 5 being the maximum, how would you evaluate X's knowledge of the maximum concessions that you can make? Alba:
(1)
(2)
(3)
(4)

Medatia:
(1)
(2)
(3)
(4)

Tristat:
(1)
(2)
(3)

(4)

(5)

Vanin:

(1)

(2)

(3)

(4) 
7. Do you think there is a zone of agreement with:

$\begin{array}{lrrrr}\text { Alba } & \text { Yes } & & \text { No } & \text { Do not know } \\ \text { Medatia Yes } & & \text { No } & & \text { Do not know } \\ \text { Tristat } & \text { Yes } & & \text { No } & \text { Do not know } \\ \text { Vanin } & \text { Yes } & \text { No } & \text { Do not know }\end{array}$

8. On a 1 to 5 scale, 5 being the maximum, how would you evaluate the truthfulness of X's claims? Alba:
(1)
(2)
(3)
(4)

(5)

Medatia:
(1)
(2)
(3)
(4)

Tristat:
(1)
(2)
(3)
(4)

Vanin:

(1)

(2)

(3)

(4)

9. Have you asked the Minister to modify his/her initial instructions since yesterday? If yes, on which products or sectors?
Yes
No 
1. Are you satisfied with the state of negotiations up to now?

least satisfied

(1) partially

(2) moderately

(3) fairly

(4) fully satisfied

(5)

Why ?

2. Are the instructions you initially gave to your team different from cabinet orders ? If yes, on what bilateral and on which products?

Yes $\quad$ No

3. Have you changed the instructions that you initially gave to your ambassador ? If yes, how many $\underline{\text { times, and for what bilateral? }}$

Yes $\quad$ No

4. Do you think there is still room to be more flexible with your ambassador, if needed ? If yes, on which sectors or products?

Yes

No 


\section{APPENDIX 3: Debriefing questionnaire}

1. Have you ever participated to any real negotiations?
Yes
No

1.2. If yes, what did you find were the major similarities between the simulation and reality?

a)

b)

c)

1.3. What were the major differences between the simulation and reality?

a)

b)

c)

2. Do you think the following were major problems in the negotiating process?

a) Lack of flexibility from other country(ies)

Yes

No

If yes, which country(ies)?

b) Lack of flexibility from your own Minister

Yes

No

c) Unrealistic ministerial instructions for your team

Yes

No

d) Unrealistic initial requests from other countries

Yes

No

If yes, which one(s) ? 
If yes, which team(s)?

f) Lack of knowledge about other countries' bottom line

If yes, which country(ies)?

3. Did you make some concessions in order to get concessions on other issues more important to you? If yes, please give an example :

4. Did you form or try to form a coalition? If yes, with whom and for what purposes? 
APPENDIX 4: DATA COLLECTED ON ALL EXERCISES

Matching of mutual knowledge. Exercise $n^{\circ} 1$

\begin{tabular}{|c|c|c|c|c|c|c|c|}
\hline & \multicolumn{3}{|c|}{ A - M } & \multicolumn{3}{c|}{ M - A } & \\
\hline $\begin{array}{c}\text { A's knowledge of max } \\
\text { concession by M }\end{array}$ & 3 & 2 & 4 & 2 & 5 & 4 & $\begin{array}{c}\text { M's knowledge of max } \\
\text { concession by A }\end{array}$ \\
\hline $\begin{array}{c}\text { M's evaluation of this } \\
\text { knowledge }\end{array}$ & 4 & 5 & 2 & 4 & 2 & 4 & $\begin{array}{c}\text { A's evaluation of this } \\
\text { knowledge }\end{array}$ \\
\hline Zone of agreement with M & Y & $?$ & Y & Y & Y & Y & Zone of agreement with A \\
\hline & D1 & D2 & D3 & D1 & D2 & D3 & \\
\hline
\end{tabular}

\begin{tabular}{|c|c|c|c|c|c|c|c|}
\hline & \multicolumn{3}{|c|}{ A - T } & \multicolumn{3}{c|}{ T - A } & \\
\hline $\begin{array}{c}\text { A's knowledge of max } \\
\text { concession by T }\end{array}$ & 4 & 2 & 4 & 1 & 4 & 4 & $\begin{array}{c}\text { T's knowledge of max } \\
\text { concession by A }\end{array}$ \\
\hline T's evaluation of this knowledge & 1 & 4 & 4 & 4 & 2 & 4 & $\begin{array}{c}\text { A's evaluation of this } \\
\text { knowledge }\end{array}$ \\
\hline Zone of agreement with T & $?$ & $?$ & Y & $?$ & Y & Y & Zone of agreement with A \\
\hline & D1 & D2 & D3 & D1 & D2 & D3 & \\
\hline
\end{tabular}

\begin{tabular}{|c|c|c|c|c|c|c|c|}
\hline & \multicolumn{3}{|c|}{ A - V } & \multicolumn{3}{c|}{ V - A } & \\
\hline $\begin{array}{c}\text { A's knowledge of max } \\
\text { concession by V }\end{array}$ & 4 & 5 & 4 & $\ldots$ & 3 & 4 & $\begin{array}{c}\text { V's knowledge of max } \\
\text { concession by A }\end{array}$ \\
\hline $\begin{array}{c}\text { V's evaluation of this } \\
\text { knowledge }\end{array}$ & 4 & 1 & 4 & 3 & 2 & 4 & $\begin{array}{c}\text { A's evaluation of this } \\
\text { knowledge }\end{array}$ \\
\hline Zone of agreement with V & $?$ & Y & Y & $\ldots$ & Y & Y & Zone of agreement with A \\
\hline & D1 & D2 & D3 & D1 & D2 & D3 & \\
\hline
\end{tabular}

\begin{tabular}{|c|c|c|c|c|c|c|c|}
\hline & \multicolumn{3}{|c|}{ M - T } & \multicolumn{3}{c|}{ T - M } & \\
\hline $\begin{array}{c}\text { M's knowledge of max } \\
\text { concession by T }\end{array}$ & 3 & 3 & 1 & 1 & 4 & 4 & $\begin{array}{c}\text { T's knowledge of max } \\
\text { concession by M }\end{array}$ \\
\hline T's evaluation of this knowledge & 1 & 4 & 4 & 4 & 3 & 1 & $\begin{array}{c}\text { M's evaluation of this } \\
\text { knowledge }\end{array}$ \\
\hline Zone of agreement with T & $?$ & $?$ & $?$ & $?$ & Y & N & Zone of agreement with M \\
\hline & D1 & D2 & D3 & D1 & D2 & D3 & \\
\hline
\end{tabular}

\begin{tabular}{|c|c|c|c|c|c|c|c|}
\hline & \multicolumn{3}{|c|}{ M - V } & \multicolumn{3}{c|}{ V - M } & \\
\hline $\begin{array}{c}\text { M's knowledge of max } \\
\text { concession by V }\end{array}$ & 1 & 1 & 5 & $\ldots$ & 3 & 4 & $\begin{array}{c}\text { V's knowledge of max } \\
\text { concession by M }\end{array}$ \\
\hline V's evaluation of this knowledge & $\ldots$ & 1 & 4 & 4 & 1 & 5 & $\begin{array}{c}\text { M's evaluation of this } \\
\text { knowledge }\end{array}$ \\
\hline Zone of agreement with V & N & N & Y & $\ldots$ & Y & Y & Zone of agreement with M \\
\hline & D1 & D2 & D3 & D1 & D2 & D3 & \\
\hline
\end{tabular}

\begin{tabular}{|c|c|c|c|c|c|c|c|}
\hline & \multicolumn{3}{|c|}{ T-V } & \multicolumn{3}{c|}{ V - T } & \\
\hline $\begin{array}{c}\text { T's knowledge of max } \\
\text { concession by V }\end{array}$ & 1 & 3 & 3 & $\ldots$ & 3 & 3 & $\begin{array}{c}\text { V's knowledge of max } \\
\text { concession by T }\end{array}$ \\
\hline V's evaluation of this knowledge & $\ldots$ & 1 & 2 & 1 & 3 & 3 & T's evaluation of this knowledge \\
\hline Zone of agreement with V & $?$ & $?$ & Y & $\ldots$ & $?$ & $?$ & Zone of agreement with T \\
\hline & D1 & D2 & D3 & D1 & D2 & D3 & \\
\hline
\end{tabular}


Matching of mutual knowledge. Exercise $n^{\circ} 2$

\begin{tabular}{|c|c|c|c|c|c|c|c|}
\hline & \multicolumn{3}{|c|}{ A - M } & \multicolumn{3}{c|}{ M - A } & \\
\hline $\begin{array}{c}\text { A's knowledge of max } \\
\text { concession by M }\end{array}$ & 3 & 3 & $\ldots$ & 2 & 5 & 5 & $\begin{array}{c}\text { M's knowledge of max } \\
\text { concession by A }\end{array}$ \\
\hline $\begin{array}{c}\text { M's evaluation of this } \\
\text { knowledge }\end{array}$ & 1 & 5 & 5 & 3 & 3 & $\cdots$ & $\begin{array}{c}\text { A's evaluation of this } \\
\text { knowledge }\end{array}$ \\
\hline Zone of agreement with M & $?$ & Y & $\ldots$ & Y & Y & Y & Zone of agreement with A \\
\hline & D1 & D2 & D3 & D1 & D2 & D3 & \\
\hline
\end{tabular}

\begin{tabular}{|c|c|c|c|c|c|c|c|}
\hline & \multicolumn{3}{|c|}{ A - T } & \multicolumn{3}{c|}{ T - A } & \\
\hline $\begin{array}{c}\text { A's knowledge of max } \\
\text { concession by T }\end{array}$ & 4 & 4 & $\cdots$ & 4 & 4 & 4 & $\begin{array}{c}\text { T's knowledge of max } \\
\text { concession by A }\end{array}$ \\
\hline T's evaluation of this knowledge & 3 & 4 & 4 & 4 & 4 & $\cdots$ & $\begin{array}{c}\text { A's evaluation of this } \\
\text { knowledge }\end{array}$ \\
\hline Zone of agreement with T & Y & Y & $\ldots$ & Y & Y & Y & Zone of agreement with A \\
\hline & D1 & D2 & D3 & D1 & D2 & D3 & \\
\hline
\end{tabular}

\begin{tabular}{|c|c|c|c|c|c|c|c|}
\hline & \multicolumn{5}{|c|}{ A - V } & \multicolumn{3}{c|}{ V - A } & \\
\hline $\begin{array}{c}\text { A's knowledge of max } \\
\text { concession by V }\end{array}$ & 3 & 4 & $\cdots$ & $\cdots$ & 4 & $\cdots$ & $\begin{array}{c}\text { V's knowledge of max } \\
\text { concession by A }\end{array}$ \\
\hline $\begin{array}{c}\text { V's evaluation of this } \\
\text { knowledge }\end{array}$ & 3 & 4 & 4 & 3 & 4 & $\cdots$ & $\begin{array}{c}\text { A's evaluation of this } \\
\text { knowledge }\end{array}$ \\
\hline Zone of agreement with V & $?$ & Y & $\ldots$ & $?$ & Y & $\cdots$ & Zone of agreement with A \\
\hline & D1 & D2 & D3 & D1 & D2 & D3 & \\
\hline
\end{tabular}

\begin{tabular}{|c|c|c|c|c|c|c|c|}
\hline & \multicolumn{3}{|c|}{ M - T } & \multicolumn{3}{c|}{ T - M } & \\
\hline $\begin{array}{c}\text { M's knowledge of max } \\
\text { concession by T }\end{array}$ & 3 & 4 & 4 & 5 & 4 & 3 & $\begin{array}{c}\text { T's knowledge of max } \\
\text { concession by M }\end{array}$ \\
\hline T's evaluation of this knowledge & 4 & 3 & 4 & 4 & 3 & 5 & $\begin{array}{c}\text { M's evaluation of this } \\
\text { knowledge }\end{array}$ \\
\hline Zone of agreement with T & $?$ & Y & N & $?$ & $?$ & $?$ & Zone of agreement with M \\
\hline & D1 & D2 & D3 & D1 & D2 & D3 & \\
\hline
\end{tabular}

\begin{tabular}{|c|c|c|c|c|c|c|c|}
\hline & \multicolumn{3}{|c|}{ M - V } & \multicolumn{3}{c|}{ V - M } & \\
\hline $\begin{array}{c}\text { M's knowledge of max } \\
\text { concession by V }\end{array}$ & 1 & 5 & 4 & 3 & 4 & $\ldots$ & $\begin{array}{c}\text { V's knowledge of max } \\
\text { concession by M }\end{array}$ \\
\hline V's evaluation of this knowledge & 4 & 3 & $\ldots$ & 1 & 5 & 4 & $\begin{array}{c}\text { M's evaluation of this } \\
\text { knowledge }\end{array}$ \\
\hline Zone of agreement with V & Y & Y & Y & Y & Y & $\ldots$ & Zone of agreement with M \\
\hline & D1 & D2 & D3 & D1 & D2 & D3 & \\
\hline
\end{tabular}

\begin{tabular}{|c|c|c|c|c|c|c|c|}
\hline & \multicolumn{3}{|c|}{ T-V } & \multicolumn{3}{c|}{ V - T } & \\
\hline $\begin{array}{c}\text { T's knowledge of max } \\
\text { concession by V }\end{array}$ & 5 & 4 & 4 & 3 & 4 & $\ldots$ & $\begin{array}{c}\text { V's knowledge of max } \\
\text { concession by T }\end{array}$ \\
\hline V's evaluation of this knowledge & 4 & 3 & $\ldots$ & 3 & 3 & 4 & T's evaluation of this knowledge \\
\hline Zone of agreement with V & $?$ & $?$ & Y & $?$ & Y & $\ldots$ & Zone of agreement with T \\
\hline & D1 & D2 & D3 & D1 & D2 & D3 & \\
\hline
\end{tabular}


Matching of mutual knowledge. Exercise $n^{\circ} 3$

\begin{tabular}{|c|c|c|c|c|c|c|c|}
\hline & \multicolumn{3}{|c|}{ A - M } & \multicolumn{3}{c|}{ M - A } & \\
\hline $\begin{array}{c}\text { A's knowledge of max } \\
\text { concession by M }\end{array}$ & $\cdots$ & 2 & 4 & 4 & 3 & 4 & $\begin{array}{c}\text { M's knowledge of max } \\
\text { concession by A }\end{array}$ \\
\hline $\begin{array}{c}\text { M's evaluation of this } \\
\text { knowledge }\end{array}$ & 3 & 2 & $\cdots$ & $\cdots$ & $\cdots$ & 4 & $\begin{array}{c}\text { A's evaluation of this } \\
\text { knowledge }\end{array}$ \\
\hline Zone of agreement with M & Y & Y & Y & Y & N & Y & Zone of agreement with A \\
\hline & D1 & D2 & D3 & D1 & D2 & D3 & \\
\hline
\end{tabular}

\begin{tabular}{|c|c|c|c|c|c|c|c|}
\hline & \multicolumn{3}{|c|}{ A - T } & \multicolumn{3}{c|}{ T - A } & \\
\hline $\begin{array}{c}\text { A's knowledge of max } \\
\text { concession by T }\end{array}$ & $\cdots$ & $\cdots$ & 4 & $\cdots$ & 3 & 3 & $\begin{array}{c}\text { T's knowledge of max } \\
\text { concession by A }\end{array}$ \\
\hline T's evaluation of this knowledge & $\ldots$ & $\ldots$ & 2 & $\cdots$ & $\cdots$ & 4 & $\begin{array}{c}\text { A's evaluation of this } \\
\text { knowledge }\end{array}$ \\
\hline Zone of agreement with T & $?$ & $?$ & Y & Y & Y & Y & Zone of agreement with A \\
\hline & D1 & D2 & D3 & D1 & D2 & D3 & \\
\hline
\end{tabular}

\begin{tabular}{|c|c|c|c|c|c|c|c|}
\hline & \multicolumn{3}{|c|}{ A - V } & \multicolumn{3}{c|}{ V - A } & \\
\hline $\begin{array}{c}\text { A's knowledge of max } \\
\text { concession by V }\end{array}$ & $\cdots$ & $\cdots$ & 4 & $\cdots$ & 3 & 4 & $\begin{array}{c}\text { V's knowledge of max } \\
\text { concession by A }\end{array}$ \\
\hline $\begin{array}{c}\text { V's evaluation of this } \\
\text { knowledge }\end{array}$ & $\cdots$ & 2 & 4 & $\cdots$ & $\cdots$ & 4 & $\begin{array}{c}\text { A's evaluation of this } \\
\text { knowledge }\end{array}$ \\
\hline Zone of agreement with V & $?$ & $?$ & $?$ & N & Y & N & Zone of agreement with A \\
\hline & D1 & D2 & D3 & D1 & D2 & D3 & \\
\hline
\end{tabular}

\begin{tabular}{|c|c|c|c|c|c|c|c|}
\hline & \multicolumn{3}{|c|}{ M - T } & \multicolumn{3}{c|}{ T - M } & \\
\hline $\begin{array}{c}\text { M's knowledge of max } \\
\text { concession by T }\end{array}$ & 3 & 3 & 3 & $\ldots$ & 3 & 2 & $\begin{array}{c}\text { T's knowledge of max } \\
\text { concession by M }\end{array}$ \\
\hline T's evaluation of this knowledge & $\ldots$ & $\ldots$ & 2 & 1 & 3 & $\cdots$ & $\begin{array}{c}\text { M's evaluation of this } \\
\text { knowledge }\end{array}$ \\
\hline Zone of agreement with T & $?$ & Y & Y & Y & Y & Y & Zone of agreement with M \\
\hline & D1 & D2 & D3 & D1 & D2 & D3 & \\
\hline
\end{tabular}

\begin{tabular}{|c|c|c|c|c|c|c|c|}
\hline & \multicolumn{3}{|c|}{ M - V } & \multicolumn{3}{c|}{ V - M } & \\
\hline $\begin{array}{c}\text { M's knowledge of max } \\
\text { concession by V }\end{array}$ & 1 & 3 & 4 & $\ldots$ & 2 & 4 & $\begin{array}{c}\text { V's knowledge of max } \\
\text { concession by M }\end{array}$ \\
\hline V's evaluation of this knowledge & $\ldots$ & 2 & 4 & 2 & 3 & $\cdots$ & $\begin{array}{c}\text { M's evaluation of this } \\
\text { knowledge }\end{array}$ \\
\hline Zone of agreement with V & Y & Y & Y & N & N & N & Zone of agreement with M \\
\hline & D1 & D2 & D3 & D1 & D2 & D3 & \\
\hline
\end{tabular}

\begin{tabular}{|c|c|c|c|c|c|c|c|}
\hline & \multicolumn{3}{|c|}{ T - V } & \multicolumn{3}{c|}{ V - T } & \\
\hline $\begin{array}{c}\text { T's knowledge of max } \\
\text { concession by V }\end{array}$ & $\ldots$ & 2 & 3 & $\ldots$ & 3 & 4 & $\begin{array}{c}\text { V's knowledge of max } \\
\text { concession by T }\end{array}$ \\
\hline V's evaluation of this knowledge & $\ldots$ & 2 & 2 & $\ldots$ & $\ldots$ & 2 & T's evaluation of this knowledge \\
\hline Zone of agreement with V & Y & $?$ & Y & $?$ & N & Y & Zone of agreement with T \\
\hline & D1 & D2 & D3 & D1 & D2 & D3 & \\
\hline
\end{tabular}


Matching of mutual knowledge. Exercise $n^{\circ} 4$

\begin{tabular}{|c|c|c|c|c|c|c|c|}
\hline & \multicolumn{3}{|c|}{ A - M } & \multicolumn{3}{c|}{ M - A } & \\
\hline $\begin{array}{c}\text { A's knowledge of max } \\
\text { concession by M }\end{array}$ & 3 & 4 & 4 & 5 & 4 & 5 & $\begin{array}{c}\text { M's knowledge of max } \\
\text { concession by A }\end{array}$ \\
\hline $\begin{array}{c}\text { M's evaluation of this } \\
\text { knowledge }\end{array}$ & 4 & 4 & 4 & 3 & 3 & 4 & $\begin{array}{c}\text { A's evaluation of this } \\
\text { knowledge }\end{array}$ \\
\hline Zone of agreement with M & Y & Y & Y & Y & Y & Y & Zone of agreement with A \\
\hline & D1 & D2 & D3 & D1 & D2 & D3 & \\
\hline
\end{tabular}

\begin{tabular}{|c|c|c|c|c|c|c|c|}
\hline & \multicolumn{3}{|c|}{ A - T } & \multicolumn{3}{c|}{ T - A } & \\
\hline $\begin{array}{c}\text { A's knowledge of max } \\
\text { concession by T }\end{array}$ & 1 & 2 & 4 & 4 & 3 & 4 & $\begin{array}{c}\text { T's knowledge of max } \\
\text { concession by A }\end{array}$ \\
\hline T's evaluation of this knowledge & 4 & 3 & 4 & 1 & 2 & 4 & $\begin{array}{c}\text { A's evaluation of this } \\
\text { knowledge }\end{array}$ \\
\hline Zone of agreement with T & N & $?$ & Y & Y & Y & Y & Zone of agreement with A \\
\hline & D1 & D2 & D3 & D1 & D2 & D3 & \\
\hline
\end{tabular}

\begin{tabular}{|c|c|c|c|c|c|c|c|}
\hline & \multicolumn{3}{|c|}{ A - V } & \multicolumn{3}{c|}{ V - A } & \\
\hline $\begin{array}{c}\text { A's knowledge of max } \\
\text { concession by V }\end{array}$ & 4 & 2 & 3 & 3 & 3 & 4 & $\begin{array}{c}\text { V's knowledge of max } \\
\text { concession by A }\end{array}$ \\
\hline $\begin{array}{c}\text { V's evaluation of this } \\
\text { knowledge }\end{array}$ & 3 & 4 & 3 & 4 & 2 & 3 & $\begin{array}{c}\text { A's evaluation of this } \\
\text { knowledge }\end{array}$ \\
\hline Zone of agreement with V & Y & $?$ & Y & Y & Y & Y & Zone of agreement with A \\
\hline & D1 & D2 & D3 & D1 & D2 & D3 & \\
\hline
\end{tabular}

\begin{tabular}{|c|c|c|c|c|c|c|c|}
\hline & \multicolumn{3}{|c|}{ M - T } & \multicolumn{3}{c|}{ T-M } & \\
\hline $\begin{array}{c}\text { M's knowledge of max } \\
\text { concession by T }\end{array}$ & 4 & 4 & 5 & 4 & 2 & 3 & $\begin{array}{c}\text { T's knowledge of max } \\
\text { concession by M }\end{array}$ \\
\hline T's evaluation of this knowledge & 2 & 3 & 3 & 4 & 3 & 4 & $\begin{array}{c}\text { M's evaluation of this } \\
\text { knowledge }\end{array}$ \\
\hline Zone of agreement with T & Y & $?$ & Y & Y & N & Y & Zone of agreement with M \\
\hline & D1 & D2 & D3 & D1 & D2 & D3 & \\
\hline
\end{tabular}

\begin{tabular}{|c|c|c|c|c|c|c|c|}
\hline & \multicolumn{3}{|c|}{ M - V } & \multicolumn{3}{c|}{ V - M } & \\
\hline $\begin{array}{c}\text { M's knowledge of max } \\
\text { concession by V }\end{array}$ & 4 & 3 & 4 & 4 & 3 & 4 & $\begin{array}{c}\text { V's knowledge of max } \\
\text { concession by M }\end{array}$ \\
\hline V's evaluation of this knowledge & 4 & 2 & 4 & 3 & 2 & 3 & $\begin{array}{c}\text { M's evaluation of this } \\
\text { knowledge }\end{array}$ \\
\hline Zone of agreement with V & Y & $?$ & Y & Y & N & $?$ & Zone of agreement with M \\
\hline & D1 & D2 & D3 & D1 & D2 & D3 & \\
\hline
\end{tabular}

\begin{tabular}{|c|c|c|c|c|c|c|c|}
\hline & \multicolumn{3}{|c|}{ T - V } & \multicolumn{3}{c|}{ V - T } & \\
\hline $\begin{array}{c}\text { T's knowledge of max } \\
\text { concession by V }\end{array}$ & 3 & 4 & 4 & 3 & 4 & 4 & $\begin{array}{c}\text { V's knowledge of max } \\
\text { concession by T }\end{array}$ \\
\hline V's evaluation of this knowledge & 3 & 3 & 3 & 3 & 4 & 4 & T's evaluation of this knowledge \\
\hline Zone of agreement with V & N & Y & Y & $?$ & Y & Y & Zone of agreement with T \\
\hline & D1 & D2 & D3 & D1 & D2 & D3 & \\
\hline
\end{tabular}


APPENDIX 5: DATA COLLECTED ON EXERCISES 2,3 AND 4

Knowledge, truthfulness and evaluation of cooperativeness. Exercise $n^{\circ} 2$

\begin{tabular}{|c|c|c|c|c|c|c|c|}
\hline & \multicolumn{3}{|c|}{ A - M } & \multicolumn{3}{c|}{ M - A } & \\
\hline $\begin{array}{c}\text { A's knowledge of max } \\
\text { concessions by M }\end{array}$ & 3 & 3 & $\cdots$ & 2 & 5 & 5 & $\begin{array}{c}\text { M's knowledge of max } \\
\text { concessions by A }\end{array}$ \\
\hline $\begin{array}{c}\text { A's evaluation of M's } \\
\text { truthfulness }\end{array}$ & 4 & 3 & $\cdots$ & 2 & 5 & 4 & $\begin{array}{c}\text { M's evaluation of A's } \\
\text { truthfulness }\end{array}$ \\
\hline Most cooperative (for A) & $\mathrm{T}$ & $\mathrm{V}$ & $\cdots$ & $\mathrm{A}$ & $\mathrm{A}$ & $\mathrm{A}$ & Most cooperative (for M) \\
\hline Least cooperative (for A) & $\mathrm{V}$ & $\mathrm{T}$ & $\cdots$ & $\mathrm{T}$ & $\mathrm{T}$ & $\mathrm{T}$ & Least cooperative (for M) \\
\hline & $\mathrm{D} 1$ & $\mathrm{D} 2$ & $\mathrm{D} 3$ & $\mathrm{D} 1$ & $\mathrm{D} 2$ & $\mathrm{D} 3$ & \\
\hline
\end{tabular}

\begin{tabular}{|c|c|c|c|c|c|c|c|}
\hline & \multicolumn{3}{|c|}{ A - T } & \multicolumn{3}{c|}{ T - A } & \\
\hline $\begin{array}{c}\text { A's knowledge of max } \\
\text { concessions by T }\end{array}$ & 4 & 4 & $\cdots$ & 4 & 4 & 4 & $\begin{array}{c}\text { T's knowledge of max } \\
\text { concessions by A }\end{array}$ \\
\hline $\begin{array}{c}\text { A's evaluation of T's } \\
\text { truthfulness }\end{array}$ & 4 & 3 & $\cdots$ & 3 & 3 & 3 & $\begin{array}{c}\text { T's evaluation of A's } \\
\text { truthfulness }\end{array}$ \\
\hline Most cooperative (for A) & $\mathrm{T}$ & $\mathrm{V}$ & $\cdots$ & $\mathrm{A}$ & $\mathrm{A}$ & $\mathrm{A}$ & Most cooperative (for T) \\
\hline Least cooperative (for A) & $\mathrm{V}$ & $\mathrm{T}$ & $\cdots$ & $\cdots$ & $\mathrm{M}$ & $\mathrm{M}$ & Least cooperative (for T) \\
\hline & $\mathrm{D} 1$ & $\mathrm{D} 2$ & $\mathrm{D} 3$ & $\mathrm{D} 1$ & $\mathrm{D} 2$ & $\mathrm{D} 3$ & \\
\hline
\end{tabular}

\begin{tabular}{|c|c|c|c|c|c|c|c|}
\hline & \multicolumn{3}{|c|}{ A - V } & \multicolumn{3}{|c|}{ V - A } & \\
\hline $\begin{array}{c}\text { A's knowledge of max } \\
\text { concessions by V }\end{array}$ & 3 & 4 & $\cdots$ & $\cdots$ & 4 & $\cdots$ & $\begin{array}{c}\text { V's knowledge of max } \\
\text { concessions by A }\end{array}$ \\
\hline $\begin{array}{c}\text { A's evaluation of V's } \\
\text { truthfulness }\end{array}$ & 4 & 4 & $\cdots$ & $\cdots$ & 5 & $\cdots$ & $\begin{array}{c}\text { V's evaluation of A's } \\
\text { truthfulness }\end{array}$ \\
\hline Most cooperative (for A) & $\mathrm{T}$ & $\mathrm{V}$ & $\cdots$ & $\mathrm{M}$ & $\mathrm{M}$ & $\cdots$ & Most cooperative (for V) \\
\hline Least cooperative (for A) & $\mathrm{V}$ & $\mathrm{T}$ & $\cdots$ & $\mathrm{T}$ & $\mathrm{T}$ & $\cdots$ & Least cooperative (for V) \\
\hline & $\mathrm{D} 1$ & $\mathrm{D} 2$ & $\mathrm{D} 3$ & $\mathrm{D} 1$ & $\mathrm{D} 2$ & $\mathrm{D} 3$ & \\
\hline
\end{tabular}

\begin{tabular}{|c|c|c|c|c|c|c|c|}
\hline & \multicolumn{3}{|c|}{ M - T } & \multicolumn{3}{|c|}{ T M } & \\
\hline $\begin{array}{c}\text { M's knowledge of max } \\
\text { concessions by T }\end{array}$ & 3 & 4 & 4 & 5 & 4 & 3 & $\begin{array}{c}\text { T's knowledge of max } \\
\text { concessions by M }\end{array}$ \\
\hline $\begin{array}{c}\text { M's evaluation of T's } \\
\text { truthfulness }\end{array}$ & 1 & 2 & 1 & 2 & 2 & 2 & $\begin{array}{c}\text { T's evaluation of M's } \\
\text { truthfulness }\end{array}$ \\
\hline Most cooperative (for M) & A & A & A & A & A & A & Most cooperative (for T) \\
\hline Least cooperative (for M) & T & T & T & $\ldots$ & M & M & Least cooperative (for T) \\
\hline & D1 & D2 & D3 & D1 & D2 & D3 & \\
\hline
\end{tabular}




\begin{tabular}{|c|c|c|c|c|c|c|c|}
\hline & \multicolumn{3}{|c|}{ M - V } & \multicolumn{3}{c|}{ V - M } & \\
\hline $\begin{array}{c}\text { M's knowledge of max } \\
\text { concessions by V }\end{array}$ & 1 & 5 & 4 & 3 & 4 & $\cdots$ & $\begin{array}{c}\text { V's knowledge of max } \\
\text { concessions by M }\end{array}$ \\
\hline $\begin{array}{c}\text { M's evaluation of V's } \\
\text { truthfulness }\end{array}$ & 2 & 5 & 4 & 2 & 4 & $\cdots$ & $\begin{array}{c}\text { V's evaluation of M's } \\
\text { truthfulness }\end{array}$ \\
\hline Most cooperative (for M) & $\mathrm{A}$ & $\mathrm{A}$ & $\mathrm{A}$ & $\mathrm{M}$ & $\mathrm{M}$ & $\cdots$ & Most cooperative (for V) \\
\hline Least cooperative (for M) & $\mathrm{T}$ & $\mathrm{T}$ & $\mathrm{T}$ & $\mathrm{T}$ & $\mathrm{T}$ & $\cdots$ & Least cooperative (for V) \\
\hline & $\mathrm{D} 1$ & $\mathrm{D} 2$ & $\mathrm{D} 3$ & $\mathrm{D} 1$ & $\mathrm{D} 2$ & $\mathrm{D} 3$ & \\
\hline
\end{tabular}

\begin{tabular}{|c|c|c|c|c|c|c|c|}
\hline & \multicolumn{3}{|c|}{ T - V } & \multicolumn{3}{|c|}{ V - T } & \\
\hline $\begin{array}{c}\text { T's knowledge of max } \\
\text { concessions by V }\end{array}$ & 5 & 4 & 4 & 3 & 4 & $\cdots$ & $\begin{array}{c}\text { V's knowledge of max } \\
\text { concessions by T }\end{array}$ \\
\hline $\begin{array}{c}\text { T's evaluation of V's } \\
\text { truthfulness }\end{array}$ & 3 & 2 & 2 & 2 & 4 & $\cdots$ & $\begin{array}{c}\text { V's evaluation of T's } \\
\text { truthfulness }\end{array}$ \\
\hline Most cooperative (for T) & $\mathrm{A}$ & $\mathrm{A}$ & $\mathrm{A}$ & $\mathrm{M}$ & $\mathrm{M}$ & $\cdots$ & Most cooperative (for V) \\
\hline Least cooperative (for T) & $\cdots$ & $\mathrm{M}$ & $\mathrm{M}$ & $\mathrm{T}$ & $\mathrm{T}$ & $\cdots$ & Least cooperative (for V) \\
\hline & $\mathrm{D} 1$ & $\mathrm{D} 2$ & $\mathrm{D} 3$ & $\mathrm{D} 1$ & $\mathrm{D} 2$ & $\mathrm{D} 3$ & \\
\hline
\end{tabular}

Knowledge, trustfulness and evaluation of cooperativeness. Exercise $n^{\circ} 3$

\begin{tabular}{|c|c|c|c|c|c|c|c|}
\hline & \multicolumn{3}{|c|}{ A - M } & \multicolumn{3}{c|}{ M - A } & \\
\hline $\begin{array}{c}\text { A's knowledge of max } \\
\text { concessions by M }\end{array}$ & $\cdots$ & 2 & 4 & 4 & 3 & 4 & $\begin{array}{c}\text { M's knowledge of max } \\
\text { concessions by A }\end{array}$ \\
\hline $\begin{array}{c}\text { A's evaluation of M's } \\
\text { truthfulness }\end{array}$ & 4 & 4 & 4 & 3 & 2 & 4 & $\begin{array}{c}\text { M's evaluation of A's } \\
\text { truthfulness }\end{array}$ \\
\hline Most cooperative (for A) & $\mathrm{M}$ & $\mathrm{M}$ & $\mathrm{M}$ & $\mathrm{A}$ & $\mathrm{T}$ & $\mathrm{V}$ & Most cooperative (for M) \\
\hline Least cooperative (for A) & $\mathrm{T}$ & $\cdots$ & $\mathrm{V}$ & $\mathrm{T}$ & $\mathrm{A}$ & $\mathrm{T}$ & Least cooperative (for M) \\
\hline & $\mathrm{D} 1$ & $\mathrm{D} 2$ & $\mathrm{D} 3$ & $\mathrm{D} 1$ & $\mathrm{D} 2$ & $\mathrm{D} 3$ & \\
\hline
\end{tabular}

\begin{tabular}{|c|c|c|c|c|c|c|c|}
\hline & \multicolumn{3}{|c|}{ A - T } & \multicolumn{3}{c|}{ T - A } & \\
\hline $\begin{array}{c}\text { A's knowledge of max } \\
\text { concessions by T }\end{array}$ & $\ldots$ & $\cdots$ & 4 & $\ldots$ & 3 & 3 & $\begin{array}{c}\text { T's knowledge of max } \\
\text { concessions by A }\end{array}$ \\
\hline $\begin{array}{c}\text { A's evaluation of T's } \\
\text { truthfulness }\end{array}$ & 4 & 4 & 4 & $\ldots$ & 3 & 2 & $\begin{array}{c}\text { T's evaluation of A's } \\
\text { truthfulness }\end{array}$ \\
\hline Most cooperative (for A) & $\mathrm{M}$ & $\mathrm{M}$ & $\mathrm{M}$ & $\mathrm{A}$ & $\mathrm{M}$ & $\mathrm{V}$ & Most cooperative (for T) \\
\hline Least cooperative (for A) & $\mathrm{T}$ & $\ldots$ & $\mathrm{V}$ & $\cdots$ & $\mathrm{V}$ & $\ldots$ & Least cooperative (for T) \\
\hline & $\mathrm{D} 1$ & $\mathrm{D} 2$ & $\mathrm{D} 3$ & $\mathrm{D} 1$ & $\mathrm{D} 2$ & $\mathrm{D} 3$ & \\
\hline
\end{tabular}




\begin{tabular}{|c|c|c|c|c|c|c|c|}
\hline & \multicolumn{3}{|c|}{ A - V } & \multicolumn{3}{c|}{ V - A } & \\
\hline $\begin{array}{c}\text { A's knowledge of max } \\
\text { concessions by V }\end{array}$ & $\cdots$ & $\cdots$ & 4 & $\cdots$ & 3 & 4 & $\begin{array}{c}\text { V's knowledge of max } \\
\text { concessions by A }\end{array}$ \\
\hline $\begin{array}{c}\text { A's evaluation of V's } \\
\text { truthfulness }\end{array}$ & 4 & 4 & 4 & 1 & 1 & 2 & $\begin{array}{c}\text { V's evaluation of A's } \\
\text { truthfulness }\end{array}$ \\
\hline Most cooperative (for A) & $\mathrm{M}$ & $\mathrm{M}$ & $\mathrm{M}$ & $\mathrm{M}$ & $\mathrm{T}$ & $\mathrm{T}$ & Most cooperative (for V) \\
\hline Least cooperative (for A) & $\mathrm{T}$ & $\cdots$ & $\mathrm{V}$ & $\mathrm{T}$ & $\cdots$ & $\mathrm{A}$ & Least cooperative (for V) \\
\hline & $\mathrm{D} 1$ & $\mathrm{D} 2$ & $\mathrm{D} 3$ & $\mathrm{D} 1$ & $\mathrm{D} 2$ & $\mathrm{D} 3$ & \\
\hline
\end{tabular}

\begin{tabular}{|c|c|c|c|c|c|c|c|}
\hline & \multicolumn{3}{|c|}{ M - T } & \multicolumn{3}{c|}{ T - M } & \\
\hline $\begin{array}{c}\text { M's knowledge of max } \\
\text { concessions by T }\end{array}$ & 3 & 3 & 3 & $\ldots$ & 3 & 2 & $\begin{array}{c}\text { T's knowledge of max } \\
\text { concessions by M }\end{array}$ \\
\hline $\begin{array}{c}\text { M's evaluation of T's } \\
\text { truthfulness }\end{array}$ & $\ldots$ & 3 & 3 & $\ldots$ & 4 & 2 & $\begin{array}{c}\text { T's evaluation of M's } \\
\text { truthfulness }\end{array}$ \\
\hline Most cooperative (for M) & $\mathrm{A}$ & $\mathrm{T}$ & $\mathrm{V}$ & $\mathrm{A}$ & $\mathrm{M}$ & $\mathrm{V}$ & Most cooperative (for T) \\
\hline Least cooperative (for M) & $\mathrm{T}$ & $\mathrm{A}$ & $\mathrm{T}$ & $\cdots$ & $\mathrm{V}$ & $\ldots$ & Least cooperative (for T) \\
\hline & $\mathrm{D} 1$ & $\mathrm{D} 2$ & $\mathrm{D} 3$ & $\mathrm{D} 1$ & $\mathrm{D} 2$ & $\mathrm{D} 3$ & \\
\hline
\end{tabular}

\begin{tabular}{|c|c|c|c|c|c|c|c|}
\hline & \multicolumn{3}{|c|}{ M - V } & \multicolumn{3}{c|}{ V - M } & \\
\hline $\begin{array}{c}\text { M's knowledge of max } \\
\text { concessions by V }\end{array}$ & 1 & 3 & 4 & $\cdots$ & 2 & 4 & $\begin{array}{c}\text { V's knowledge of max } \\
\text { concessions by M }\end{array}$ \\
\hline $\begin{array}{c}\text { M's evaluation of V's } \\
\text { truthfulness }\end{array}$ & 3 & 3 & 4 & 3 & 1 & 3 & $\begin{array}{c}\text { V's evaluation of M's } \\
\text { truthfulness }\end{array}$ \\
\hline Most cooperative (for M) & $\mathrm{A}$ & $\mathrm{T}$ & $\mathrm{V}$ & $\mathrm{M}$ & $\mathrm{T}$ & $\mathrm{T}$ & Most cooperative (for V) \\
\hline Least cooperative (for M) & $\mathrm{T}$ & $\mathrm{A}$ & $\mathrm{T}$ & $\mathrm{T}$ & $\cdots$ & $\mathrm{A}$ & Least cooperative (for V) \\
\hline & $\mathrm{D} 1$ & $\mathrm{D} 2$ & $\mathrm{D} 3$ & $\mathrm{D} 1$ & $\mathrm{D} 2$ & $\mathrm{D} 3$ & \\
\hline
\end{tabular}

\begin{tabular}{|c|c|c|c|c|c|c|c|}
\hline & \multicolumn{3}{|c|}{ T - V } & \multicolumn{3}{c|}{ V - T } & \\
\hline $\begin{array}{c}\text { T's knowledge of max } \\
\text { concessions by V }\end{array}$ & $\cdots$ & 2 & 3 & $\cdots$ & 3 & 4 & $\begin{array}{c}\text { V's knowledge of max } \\
\text { concessions by T }\end{array}$ \\
\hline $\begin{array}{c}\text { T's evaluation of V's } \\
\text { truthfulness }\end{array}$ & $\cdots$ & 2 & 3 & 1 & 1 & 4 & $\begin{array}{c}\text { V's evaluation of T's } \\
\text { truthfulness }\end{array}$ \\
\hline Most cooperative (for T) & $\mathrm{A}$ & $\mathrm{M}$ & $\mathrm{V}$ & $\mathrm{M}$ & $\mathrm{T}$ & $\mathrm{T}$ & Most cooperative (for V) \\
\hline Least cooperative (for T) & $\cdots$ & $\mathrm{V}$ & $\cdots$ & $\mathrm{T}$ & $\cdots$ & $\mathrm{A}$ & Least cooperative (for V) \\
\hline & $\mathrm{D} 1$ & $\mathrm{D} 2$ & $\mathrm{D} 3$ & $\mathrm{D} 1$ & $\mathrm{D} 2$ & $\mathrm{D} 3$ & \\
\hline
\end{tabular}


Knowledge, trustfulness and evaluation of cooperativeness. Exercise $n^{\circ} 4$

\begin{tabular}{|c|c|c|c|c|c|c|c|}
\hline & \multicolumn{3}{|c|}{ A - M } & \multicolumn{3}{c|}{ M - A } & \\
\hline $\begin{array}{c}\text { A's knowledge of max } \\
\text { concessions by M }\end{array}$ & 3 & 4 & 4 & 5 & 4 & 5 & $\begin{array}{c}\text { M's knowledge of max } \\
\text { concessions by A }\end{array}$ \\
\hline $\begin{array}{c}\text { A's evaluation of M's } \\
\text { truthfulness }\end{array}$ & 4 & 4 & 4 & 5 & 5 & 5 & $\begin{array}{c}\text { M's evaluation of A's } \\
\text { truthfulness }\end{array}$ \\
\hline Most cooperative (for A) & $\mathrm{V}$ & $\mathrm{M}$ & $\mathrm{T}$ & $\mathrm{T}$ & $\mathrm{A}$ & $\mathrm{A}$ & Most cooperative (for M) \\
\hline Least cooperative (for A) & $\mathrm{T}$ & $\mathrm{T}$ & $\mathrm{V}$ & $\mathrm{V}$ & $\mathrm{T}$ & $\mathrm{V}$ & Least cooperative (for M) \\
\hline & $\mathrm{D} 1$ & $\mathrm{D} 2$ & $\mathrm{D} 3$ & $\mathrm{D} 1$ & $\mathrm{D} 2$ & $\mathrm{D} 3$ & \\
\hline
\end{tabular}

\begin{tabular}{|c|c|c|c|c|c|c|c|}
\hline & \multicolumn{3}{|c|}{ A - T } & \multicolumn{3}{c|}{ T - A } & \\
\hline $\begin{array}{c}\text { A's knowledge of max } \\
\text { concessions by T }\end{array}$ & 1 & 2 & 4 & 4 & 3 & 4 & $\begin{array}{c}\text { T's knowledge of max } \\
\text { concessions by A }\end{array}$ \\
\hline $\begin{array}{c}\text { A's evaluation of T's } \\
\text { truthfulness }\end{array}$ & 1 & 1 & 4 & 3 & 3 & 4 & $\begin{array}{c}\text { T's evaluation of A's } \\
\text { truthfulness }\end{array}$ \\
\hline Most cooperative (for A) & $\mathrm{V}$ & $\mathrm{M}$ & $\mathrm{T}$ & $\mathrm{A}$ & $\mathrm{V}$ & $\mathrm{V}$ & Most cooperative (for T) \\
\hline Least cooperative (for A) & $\mathrm{T}$ & $\mathrm{T}$ & $\mathrm{V}$ & $\mathrm{V}$ & $\mathrm{M}$ & $\mathrm{M}$ & Least cooperative (for T) \\
\hline & $\mathrm{D} 1$ & $\mathrm{D} 2$ & $\mathrm{D} 3$ & $\mathrm{D} 1$ & $\mathrm{D} 2$ & $\mathrm{D} 3$ & \\
\hline
\end{tabular}

\begin{tabular}{|c|c|c|c|c|c|c|c|}
\hline & \multicolumn{3}{|c|}{$\mathrm{A}-\mathrm{V}$} & \multicolumn{3}{|c|}{$\mathrm{V}-\mathrm{A}$} & \multicolumn{1}{|c|}{$\begin{array}{c}\text { V's knowledge of max } \\
\text { concessions by A }\end{array}$} \\
\hline $\begin{array}{c}\text { A's knowledge of max } \\
\text { concessions by V }\end{array}$ & 4 & 2 & 3 & 3 & 3 & 4 & $\begin{array}{c}\text { V's evaluation of A's } \\
\text { truthfulness }\end{array}$ \\
\hline $\begin{array}{c}\text { A's evaluation of V's } \\
\text { truthfulness }\end{array}$ & 4 & 1 & 2 & 3 & 2 & 4 & Most cooperative (for V) \\
\hline Most cooperative (for A) & $\mathrm{V}$ & $\mathrm{M}$ & $\mathrm{T}$ & $\mathrm{T}$ & $\mathrm{T}$ & $\mathrm{T}$ & Least cooperative (for V) \\
\hline Least cooperative (for A) & $\mathrm{T}$ & $\mathrm{T}$ & $\mathrm{V}$ & $\mathrm{M}$ & $\mathrm{M}$ & $\mathrm{M}$ & $\mathrm{D}$ \\
\hline & $\mathrm{D} 1$ & $\mathrm{D} 2$ & $\mathrm{D} 3$ & $\mathrm{D} 1$ & $\mathrm{D} 2$ & $\mathrm{D} 3$ & \\
\hline
\end{tabular}

\begin{tabular}{|c|c|c|c|c|c|c|c|}
\hline & \multicolumn{3}{|c|}{ M - T } & \multicolumn{3}{c|}{ T - M } & \\
\hline $\begin{array}{c}\text { M's knowledge of max } \\
\text { concessions by T }\end{array}$ & 4 & 4 & 5 & 4 & 2 & 3 & $\begin{array}{c}\text { T's knowledge of max } \\
\text { concessions by M }\end{array}$ \\
\hline $\begin{array}{c}\text { M's evaluation of T's } \\
\text { truthfulness }\end{array}$ & 4 & 4 & 4 & 4 & 1 & 2 & $\begin{array}{c}\text { T's evaluation of M's } \\
\text { truthfulness }\end{array}$ \\
\hline Most cooperative (for M) & T & A & A & A & V & V & Most cooperative (for T) \\
\hline Least cooperative (for M) & V & T & V & V & M & M & Least cooperative (for T) \\
\hline & D1 & D2 & D3 & D1 & D2 & D3 & \\
\hline
\end{tabular}




\begin{tabular}{|c|c|c|c|c|c|c|c|}
\hline & \multicolumn{3}{|c|}{ M - V } & \multicolumn{3}{c|}{ V - M } & \\
\hline $\begin{array}{c}\text { M's knowledge of max } \\
\text { concessions by V }\end{array}$ & 4 & 3 & 4 & 4 & 3 & 4 & $\begin{array}{c}\text { V's knowledge of max } \\
\text { concessions by M }\end{array}$ \\
\hline $\begin{array}{c}\text { M's evaluation of V's } \\
\text { truthfulness }\end{array}$ & 4 & 3 & 4 & 4 & 4 & 4 & $\begin{array}{c}\text { V's evaluation of M's } \\
\text { truthfulness }\end{array}$ \\
\hline Most cooperative (for M) & $\mathrm{T}$ & $\mathrm{A}$ & $\mathrm{A}$ & $\mathrm{T}$ & $\mathrm{T}$ & $\mathrm{T}$ & Most cooperative (for V) \\
\hline Least cooperative (for M) & $\mathrm{V}$ & $\mathrm{T}$ & $\mathrm{V}$ & $\mathrm{M}$ & $\mathrm{M}$ & $\mathrm{M}$ & Least cooperative (for V) \\
\hline & $\mathrm{D} 1$ & $\mathrm{D} 2$ & $\mathrm{D} 3$ & $\mathrm{D} 1$ & $\mathrm{D} 2$ & $\mathrm{D} 3$ & \\
\hline
\end{tabular}

\begin{tabular}{|c|c|c|c|c|c|c|c|}
\hline & \multicolumn{3}{|c|}{ T - V } & \multicolumn{3}{c|}{ V - T } & \\
\hline $\begin{array}{c}\text { T's knowledge of max } \\
\text { concessions by V }\end{array}$ & 3 & 4 & 4 & 3 & 4 & 4 & $\begin{array}{c}\text { V's knowledge of max } \\
\text { concessions by T }\end{array}$ \\
\hline $\begin{array}{c}\text { T's evaluation of V's } \\
\text { truthfulness }\end{array}$ & 4 & 4 & 4 & 4 & 4 & 4 & $\begin{array}{c}\text { V's evaluation of T's } \\
\text { truthfulness }\end{array}$ \\
\hline Most cooperative (for T) & $\mathrm{A}$ & $\mathrm{V}$ & $\mathrm{V}$ & $\mathrm{T}$ & $\mathrm{T}$ & $\mathrm{T}$ & Most cooperative (for V) \\
\hline Least cooperative (for T) & $\mathrm{V}$ & $\mathrm{M}$ & $\mathrm{M}$ & $\mathrm{M}$ & $\mathrm{M}$ & $\mathrm{M}$ & Least cooperative (for V) \\
\hline & $\mathrm{D} 1$ & $\mathrm{D} 2$ & $\mathrm{D} 3$ & $\mathrm{D} 1$ & $\mathrm{D} 2$ & $\mathrm{D} 3$ & \\
\hline
\end{tabular}

